\title{
New species of Acoela from the Mediterranean, the Red Sea, and the South Pacific
}

\author{
KARIN SARA NILSSON, ANDREAS WALLBERG \& ULF JONDELIUS \\ Department of Invertebrate Zoology, Swedish Museum of Natural History, Sweden \\ POB 50005, SE 104 05, Stockholm, Sweden \\ Email: karin.nilsson@nrm.se,ulf.jondelius@nrm.se,andreas.wallberg@gmail.com \\ Corresponding author: ulf.jondelius@nrm.se
}

\section{Table of contents}

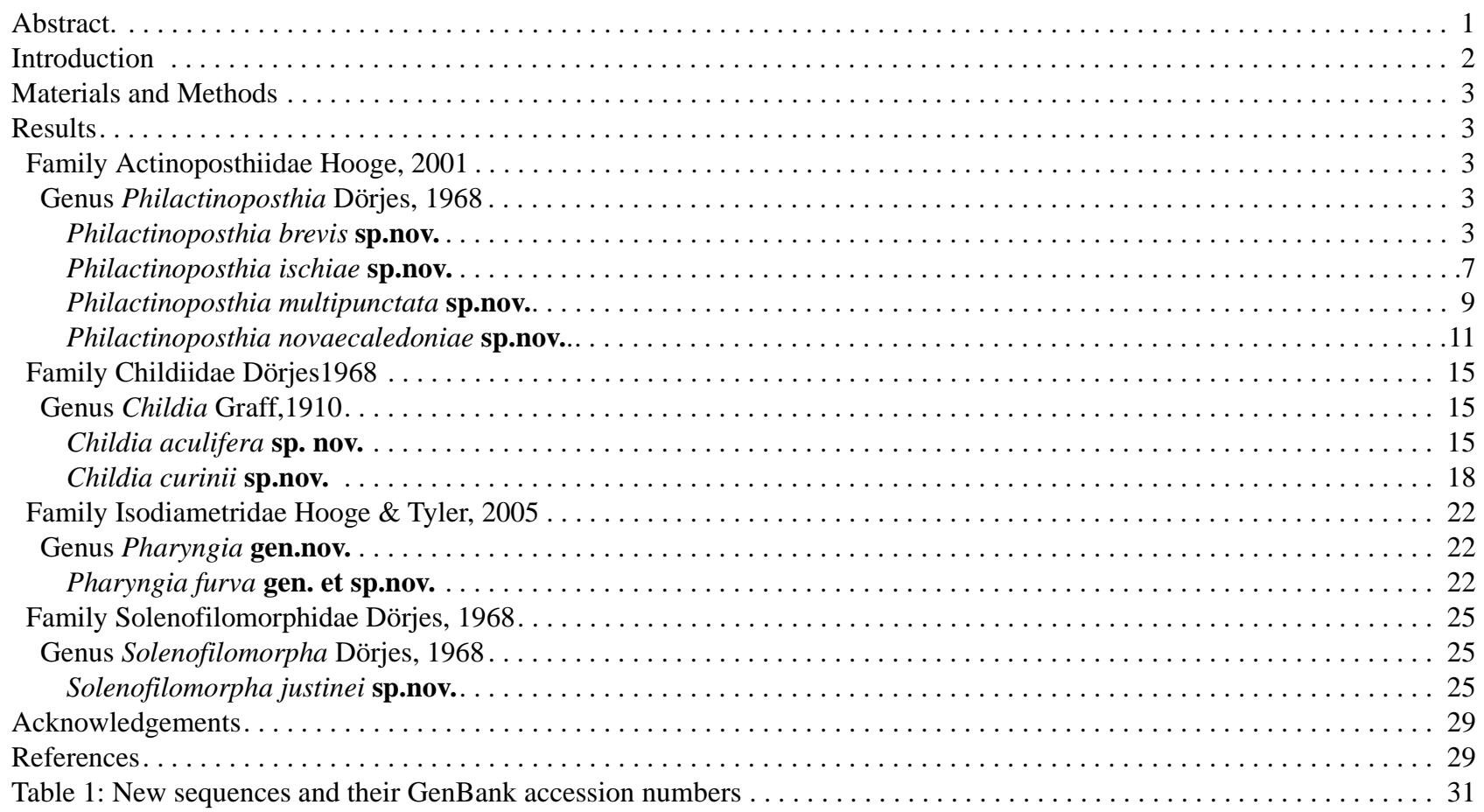

\begin{abstract}
Eight new species of Acoela are reported including the first Acoela recorded from New Caledonia and the first acoel described from volcanic carbon dioxide vents. Pharyngia furva gen. et sp.nov. (Isodiametridae) and Philactinoposthia brevis sp.nov. (Actinoposthiidae) from the Red Sea; Childia curinii sp.nov. (Childiidae), Philactinoposthia ischiae sp.nov. and Philactinoposthia multipunctata sp.nov. from the Mediterranean; Philactinoposthia novaecaledoniae sp.nov., Childia aculifera sp.nov. and Solenofilomorpha justinei sp.nov. (Solenofilomorphidae) from the South Pacific are described. Nucleotide sequences for the nuclear ribosomal 18S rRNA, 28S rRNA and the mitochondrial COI genes were determined for the new species and used in a Bayesian molecular phylogenetic analysis.
\end{abstract}

Key words: Carbon dioxide vents, Interstitial, Meiofauna, New Caledonia 


\section{Introduction}

Acoels are marine worms, with the exception of the limnic Oligochoerus limnophilus Ax \& Dörjes 1966, and Limnoposthia polonica (Kolasa \& Faubel, 1974). Most species are small, and as such part of the meiofauna of tropical, temperate and polar climates where they live interstitially in sandy or muddy sediments, among algae or in the pelagial. A few species are commensals in the intestine of echinoderms (Beklemischev, 1915; Hickman, 1956; Leiper, 1902).

The interest in Acoela has increased since new molecular findings indicated that they are the sister group of all other Bilateria and not part of the Platyhelminthes (Ruiz-Trillo et al. 1999; Ruiz-Trillo et al. 2002; Telford et al. 2003; Wallberg et al. 2007; Hejnol et al. 2009). This is also supported by their simple nervous system (Reuter et al. 2001), lack of through gut and excretory organs (Jondelius et al. 2002).

To date about 400 acoel species are described and classified into 21 families. Acoel diversity has mainly been sampled in the North East Atlantic (e.g. Westblad, 1942, 1945, 1946, 1948; Dörjes 1968), and, due to the efforts of Ernest Marcus (1948, 1950, 1954, 1957), in the Sao Paolo area in Brazil. Knowledge of the acoel fauna outside these areas is very poor. This is exemplified by the 47 species known from Gullmarsfjorden on the Swedish west coast with an area of $57 \mathrm{~km}^{2}$, whereas only 9 species are known from the 74 million $\mathrm{km}^{2}$ Indian Ocean (Haswell, 1905; Marcus, 1957; Bartolomaeus \& Balzer, 1997; Achatz \& Hooge, 2006; Achatz, 2008).

Here we report on eight new species of Acoela collected in the Mediterranean, the Red Sea and the South Pacific including the first three acoel species from New Caledonia and the first acoel from volcanic carbon dioxide vents. We have used nucleotide sequences from the nuclear ribosomal $18 \mathrm{~S}$ and $28 \mathrm{~S}$ and the mitochondrial CO1 genes to reconstruct their phylogenetic positions to aid in classification and to provide barcodes for the new species.

\section{Material and Methods}

\section{Sampling \& Microscopy}

Samples of sand sediments were collected by snorkeling or scuba diving and transported to the laboratory for extraction, observation and preservation. Specimens were extracted from the sediment using $7 \%$ magnesium-chloride solution as anesthetization (Martens, 1984). Live animals were sorted with a dissecting microscope. Squeeze preparations were viewed using an interference-contrast microscope and photographed with either a Canon EOS5D or Nikon Fi1 microscope digital camera. For histological study, specimens were fixed

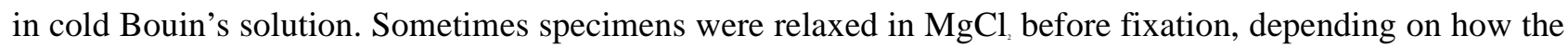
specimen reacted and their fragility.

Specimens for DNA extractions were preserved in $95 \%$ EtOH. Identification of specimens is based on observations of live animals and sectioned material.

\section{Histological serial sections}

After washing and dehydration in an ethanol series, specimens were embedded in paraffin and serially sectioned at 4-5 $\mu \mathrm{m}$ using a LKB Bromma 2218 Historange microtome. Histo-sections were stained with haematoxylin and eosin as counter stain (Aescht et al. 2010).

Nucleotide sequencing and phylogenetic analysis

Gene sequence data from the nuclear 18S, 28S ribosomal RNA genes and the mitochondrial COI gene was used to reconstruct the phylogenetic position of the new species and provide "barcodes" for their identification. Methods for DNA extraction, amplification and sequencing were the same as in Jondelius \& Wallberg et al. (in press). Nucleotide sequences from our specimens (reported in Table 1) were combined with the sequence dataset from Jondelius and Wallberg et al. (in press) resulting in a dataset of 147 acoel species.

The molecular analyses largely followed the procedure outlined by Jondelius and Wallberg et al. (in press). All sequences were aligned with the structural Q-INS-i algorithm in the program MAFFT (Katoh and Toh 2008; Katoh et al. 2009) and ambiguous positions were filtered with the program Aliscore at the default settings. The gene data were concatenated and a phylogeny was estimated by Bayesian inference using the program MrBayes (Huelsen- 
beck and Ronquist 2001; Ronquist and Huelsenbeck 2003). An individual GTR+G substitution model was applied to each gene partition. One cold MCMC chain and seven heated chains (melting temperature of 0.1) ran for 10 million generations. LnL, model parameters and the potential scale reduction factor (PSRF) were monitored for convergence. Every 1000nd tree was sampled from the last five million generations to compute a majority rule consensus tree. In this article relevant parts of the phylogenetic analyses are presented. For a detailed discussion of acoel phylogeny, character evolution and higher-level classification, we refer to Jondelius and Wallberg et al. (in press).

\section{Illustrations}

Drawings are based on live specimens and reconstruction of histological sections. The drawing programs Corel Painter Essentials 4 and Inkscape were used. The relative positions of prominent structures is indicated by setting the total body length of specimens to 100 units (U100). Microphotographs of histo-sections were taken with a Canon EOS5D digital camera attached to a Nikon Eclipse 80i microscope.

\section{Type material}

Type material consists of 4-5 $\mu \mathrm{m}$ thick serial sagittal sections of a paraffin-embedded specimens stained with hematoxylin-eosin. All type material is deposited in the Swedish Museum of Natural History (SMNH).

\section{List of Abbreviations}

a, male antrum; bn, bursal nozzle; $\mathbf{c m}$, circular muscle, col, clear outline; cop, male copulatory organ; ds, digestive central syncytium; ebg, eosinophilic body glands; fd, fibrous disc; fg, frontal glands; fgp, female gonopore; fm, foodmaterial; fsv, false seminal vesicle; $\mathbf{g}$, granules; gs, glandular secretion; ic, inclusions, Im, longitudinal muscle; $\mathbf{m}$, mouth; mgp, male gonopore; o, oocyte; p, penis; ph, pharynx; pm, pigment; rg, rhabdoid gland; sb, seminal bursa; sn, stylet needles; sp, sperm; st, statocyst; sty, stylet-like structure; $\mathbf{s v , ~ s e m i n a l ~ v e s i c l e ; ~} \mathbf{t}$, testes; $\mathbf{v}$, vacuole.

\section{Results}

Family Actinoposthiidae Hooge, 2001

Genus Philactinoposthia Dörjes, 1968

Philactinoposthia brevis sp.nov.

(Figs. 1, 2, 3)

Type Material: Holotype: SMNH Type-8041. Paratype 1: SMNH Type-8042, Paratype 2: SMNH Type-8043.

Type Locality. Red Sea, Eilat ( $29^{\circ} 30^{\prime} 2^{\prime \prime}$ N, $34^{\circ} 55^{\prime} 36^{\prime \prime}$ E), at 15 m water depth in fine sand.

Other Material examined. Living specimens in squeeze preparations; 4 sets of $4-5 \mu \mathrm{m}$ serial sagittal sections of paraffin-embedded specimens.

Etymology. Brevis = short, small in latin, and refers to the short body size, small bursal nozzle and small copulatory organ.

Description. Active swimmer. Living specimens up to $500 \mu \mathrm{m}$ long and $\sim 85 \mu \mathrm{m}$ wide. Body shape cylindric, both ends rounded. Epidermis completely ciliated with cilia that are $4 \mu \mathrm{m}$ long. Brown colored rhabdoid glands present, $10 \mu \mathrm{m}$ long, sparsely scattered across body, absent in anterior end and almost completely lacking on ventral side (Fig. 1AE). Rhabdoid glands compact with oval shape in sections, separate rods not detectable. Epidermis uncolored in transmitted light. Statocyst, $8 \mu \mathrm{m}$ in diameter, located $50 \mu \mathrm{m}$ from anterior end, U10.

Frontal organ present, cell bodies of frontal organ extend from U0 to U20. Mouth ventral, located in middle of body. Digestive central syncytium with brownish coloration, extends from U20 to U80.

Ovary unpaired, one large oocyte, extends from level of mouth to bursal nozzle, U65 to U82 (Fig. 1BDE). Female gonopore ventral, positioned posteriorly at U84, opens to small globular seminal bursa with bursal nozzle that connects anteriorly, difficult to detect in live specimens (Fig. 1BD). Bursal nozzle $\sim 30 \mu \mathrm{m}$ long with a zigzaglike appearance.

Male gonopore ventral, positioned posteriorly at U90, opens immediately to small arrow-shaped male copulatory organ with sclerotized stylet needles surrounded by sperm. At least four needles detectable, short in relation- 
ship to body size, $30 \mu \mathrm{m}$ long (Fig. 1B). Glands surrounds copulatory organ (Fig. 1D). False seminal vesicle located at proximal end of stylet-like structure. Sperm with granules (Fig. 1BC).
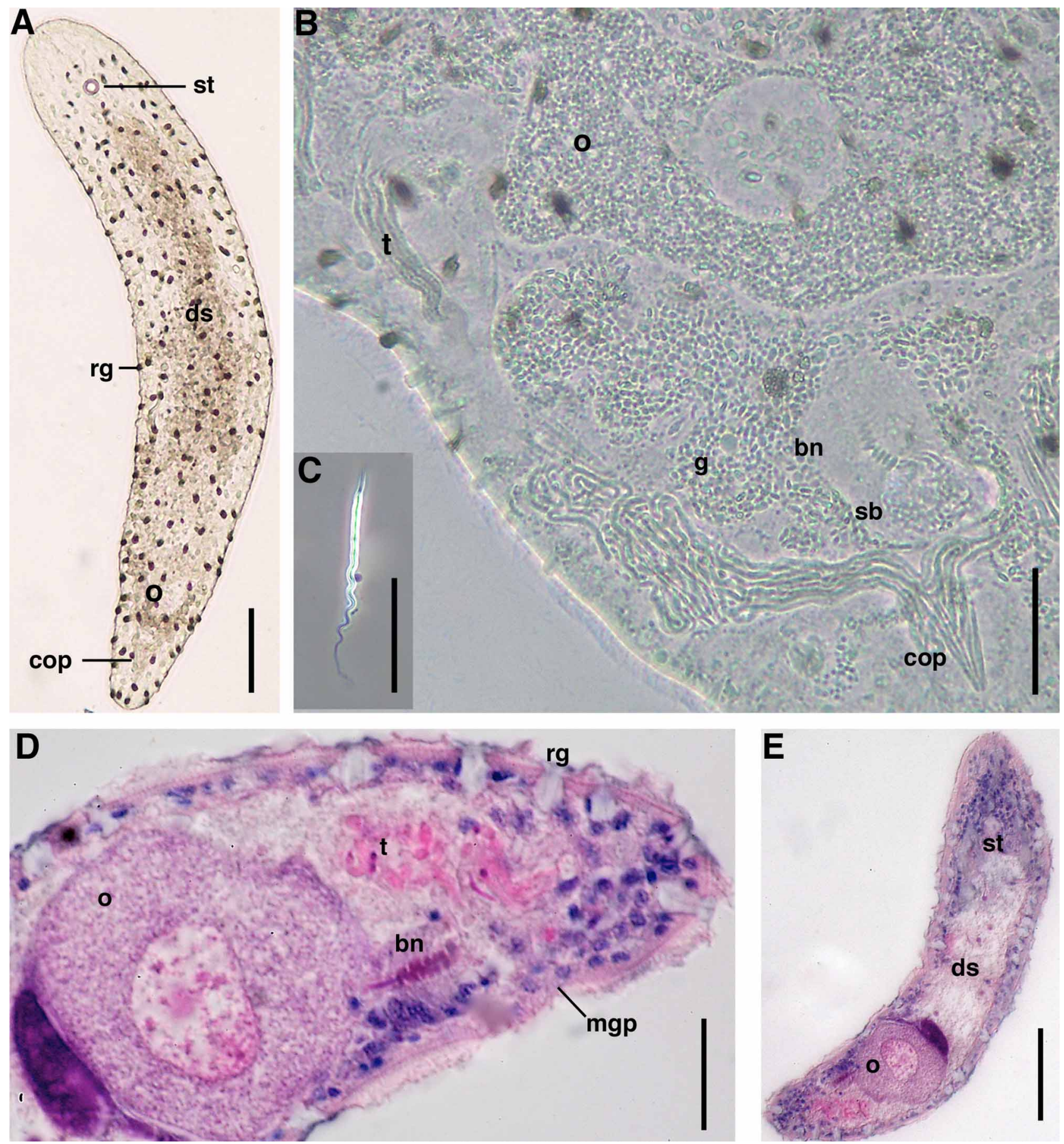

FIGURE 1. Philactinoposthia brevis sp.nov. Photomicrographs of living specimens A-C. A. Dorsal view of whole specimen. Scale bar: $60 \mu \mathrm{m} \mathrm{B}$. Dorsal view of posterior part of body. Scale bar: $40 \mu \mathrm{m}$. C. Showing sperm. Scale bar: $15 \mu \mathrm{m}$.

Photomicrographs of sagittal histological sections stained with hematoxylin-eosin D-E. D. Section through posterior part of body. Scale bar: $30 \mu \mathrm{m}$. E. Section through length of body. Scale bar: $100 \mu \mathrm{m}$. 

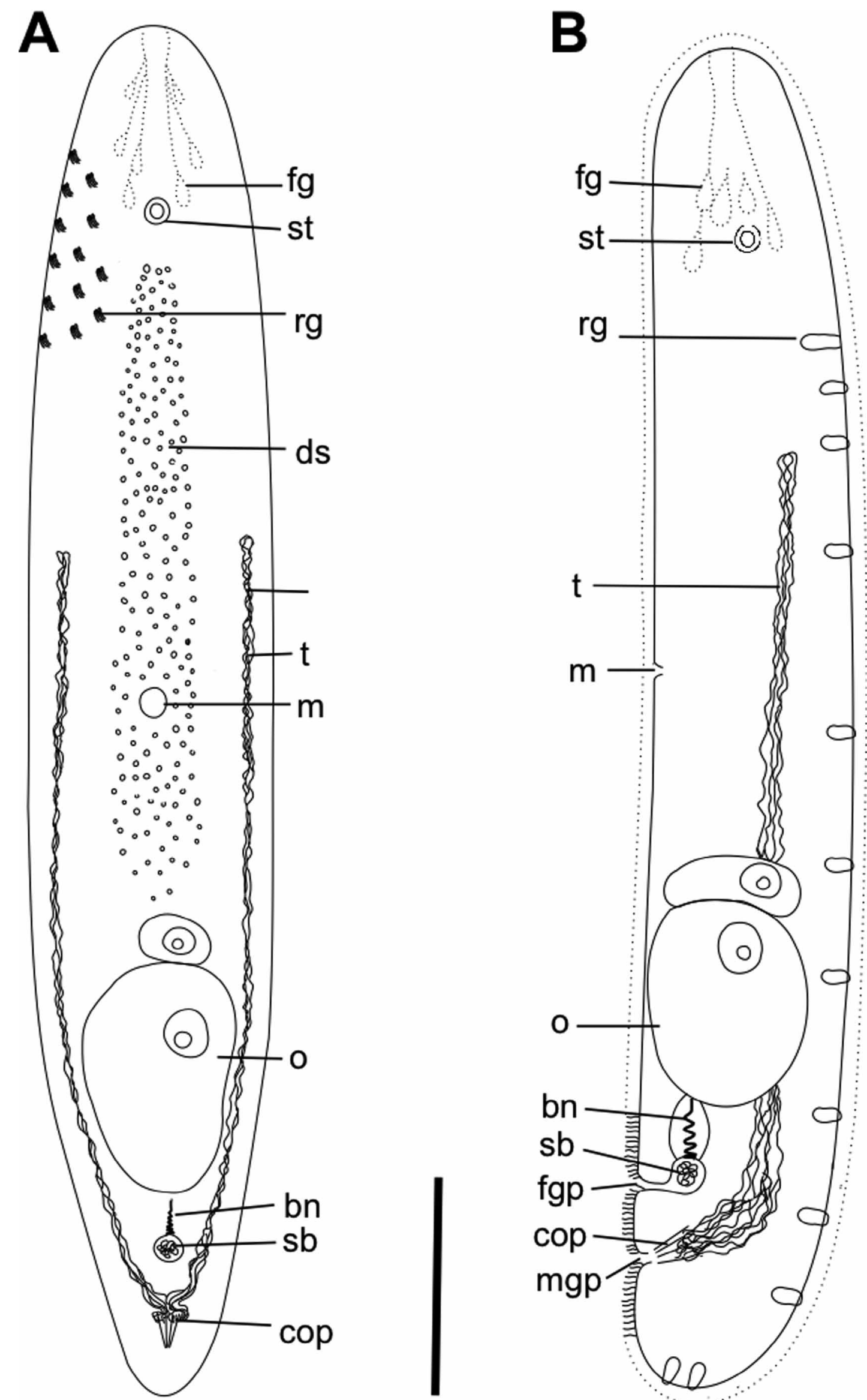

FIGURE 2. Philactinoposthia brevis sp.nov. Reconstructions show arrangement of organs. A. Dorsal reconstruction of whole living animal. B. Sagittal reconstruction of the whole animal. Scale bar: $80 \mu \mathrm{m}$. 


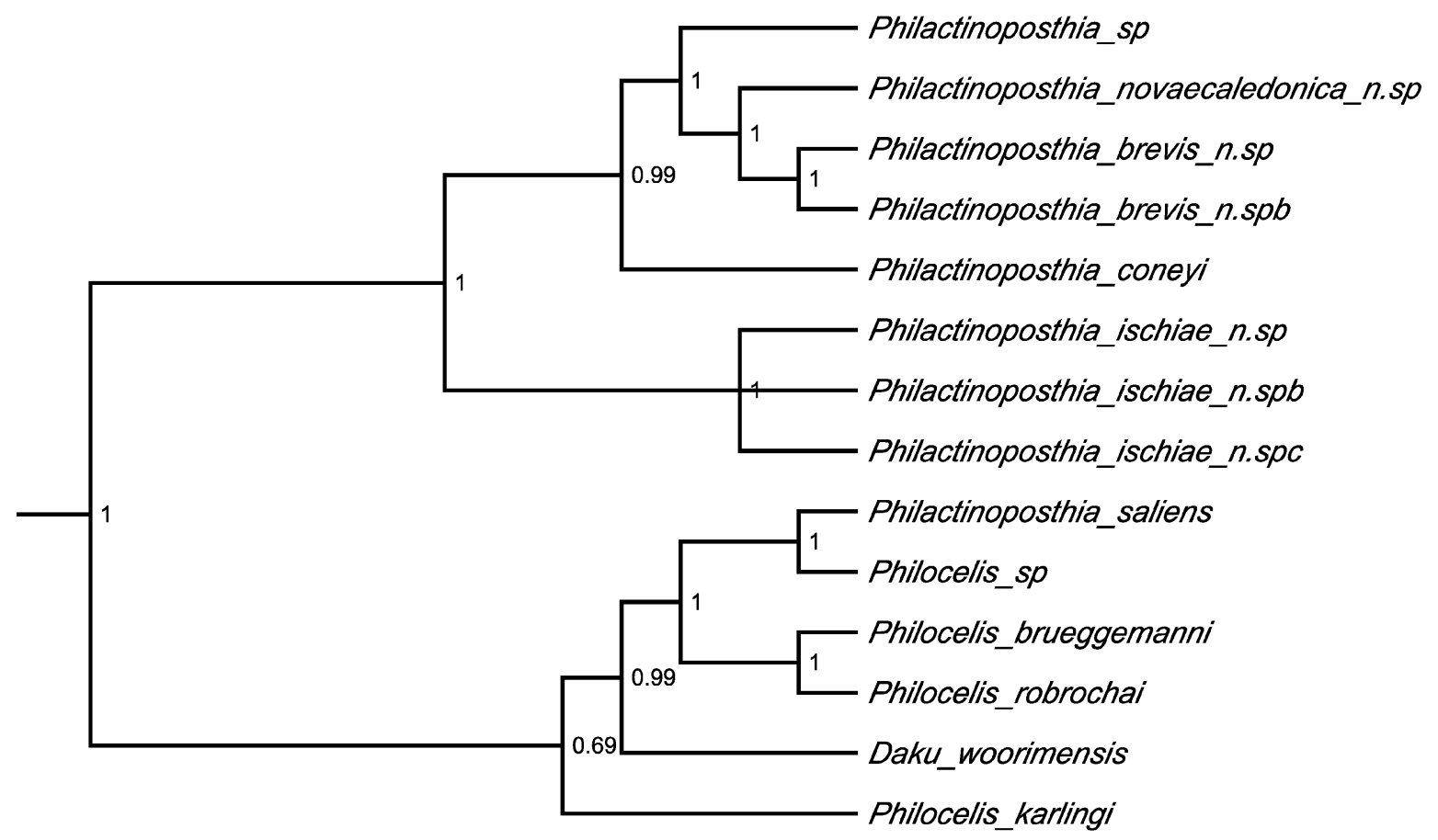

FIGURE 3. Detail from the majority rule consensus tree summarizing the result of the Bayesian analysis of the combined $18 \mathrm{~S}$ rDNA, 28S rDNA and COI dataset with the GTR+G substitution model after 10 million generations sampled every 1000 generations after a burnin of 5 million generations. $P$. brevis sp.nov., $P$. ischiae sp.nov. and $P$. novaecaledoniae sp.nov. are placed in a clade composed of Philactinoposthia species with maximum support.
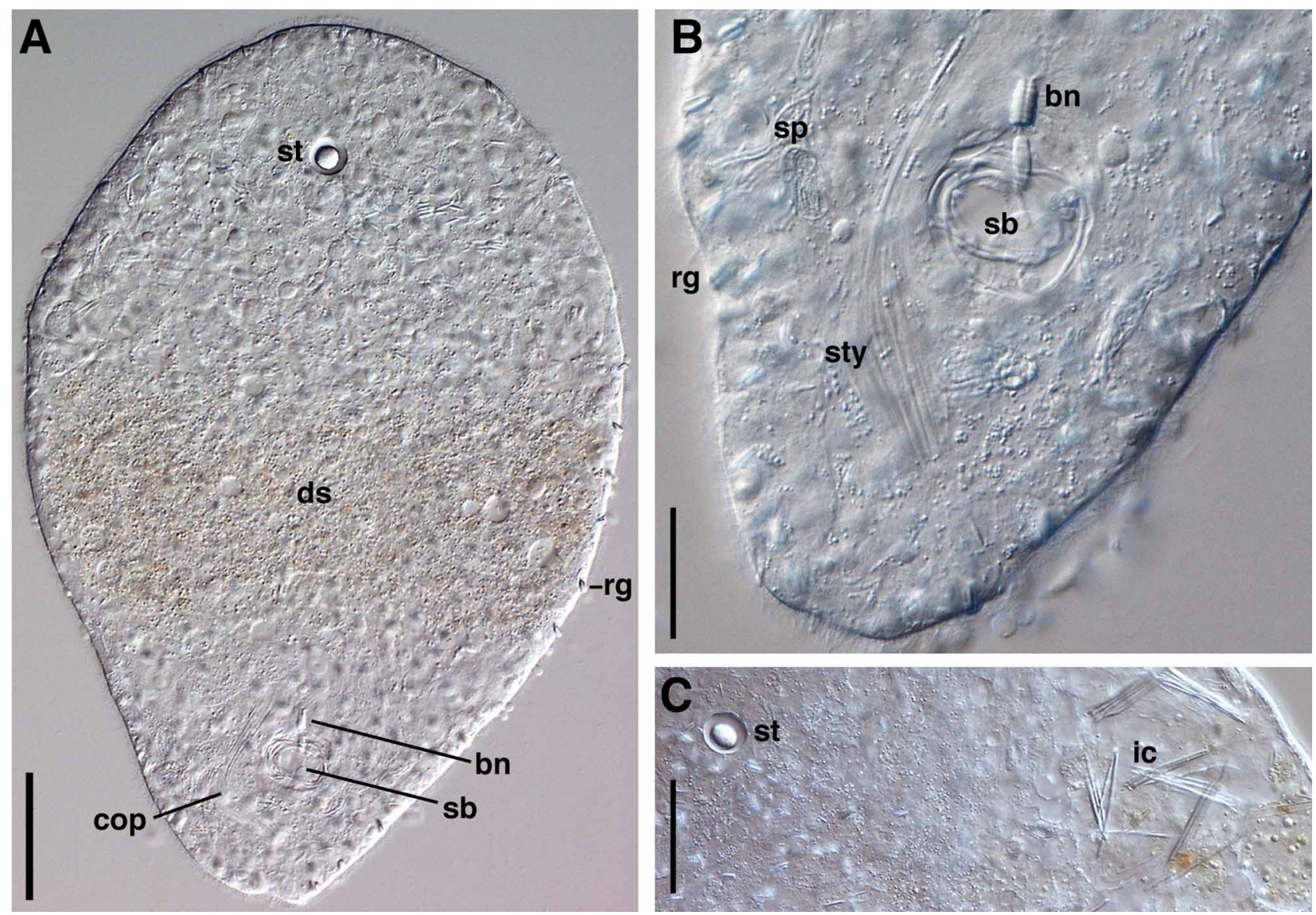

FIGURE 4. Philactinoposthia ischiae sp.nov. Photomicrographs of living specimens. A. Dorsal view of whole specimen. Scale bar: $50 \mu \mathrm{m}$. B. View of posterior part of body. Scale bar: $70 \mu \mathrm{m}$. C. Dorsal view of anterior part of body. Scale bar: 45 $\mu \mathrm{m}$. 


\section{Philactinoposthia ischiae sp.nov.}

(Figs. 3, 4, 5, 6)

Type Material: Holotype: Type SMNH-8052. Paratype 1: SMNH Type-8053, Paratype 2: SMNH Type-8054.

Type Locality. Ischia, Bay of Naples, Italy, at the volcanic carbon dioxide vent (station N3) with mean surface pH: 7.09 (Hall-Spencer et al. 2008), from 2-3 m water depth in fine sand. (40 $43^{\prime} 55^{\prime \prime} \mathrm{N}, 13^{\circ} 57^{\prime} 50^{\prime \prime} \mathrm{E}$ ).

Other Material examined. Living specimens in squeeze preparations; 3 sets of $4-5 \mu \mathrm{m}$ serial sagittal sections of paraffin-embedded specimen.

Etymology. Species epithet refers to name of type locality.

Description. Active swimmers. Living specimens $\sim 400-600 \mu \mathrm{m}$ long and $\sim 180 \mu \mathrm{m}$ wide. Anterior and posterior end rounded. Body cylindrical. Epidermis completely ciliated. Uncolored rhabdoid glands uniformly scattered across body, very small, appearing white in incident light, not visible in sections (Fig. 4AB). Body colorless in transmitted light, except some light brown coloration of digestive syncytium in some specimens (Fig. 4A). Statocyst located $50 \mu \mathrm{m}$ behind anterior end, at U12. Frontal organ present, cell bodies of frontal glands extend from U20 to U30. Mouth opening ventral, middle of body, at U50. Digestive central syncytium extends from U40 to U70 (Fig. 5AC). One specimen with large needle-like structures, 40-50 $\mu \mathrm{m}$ long, located around middle of body which is the same location as digestive syncytium thus possibly food material (Fig. 4C).
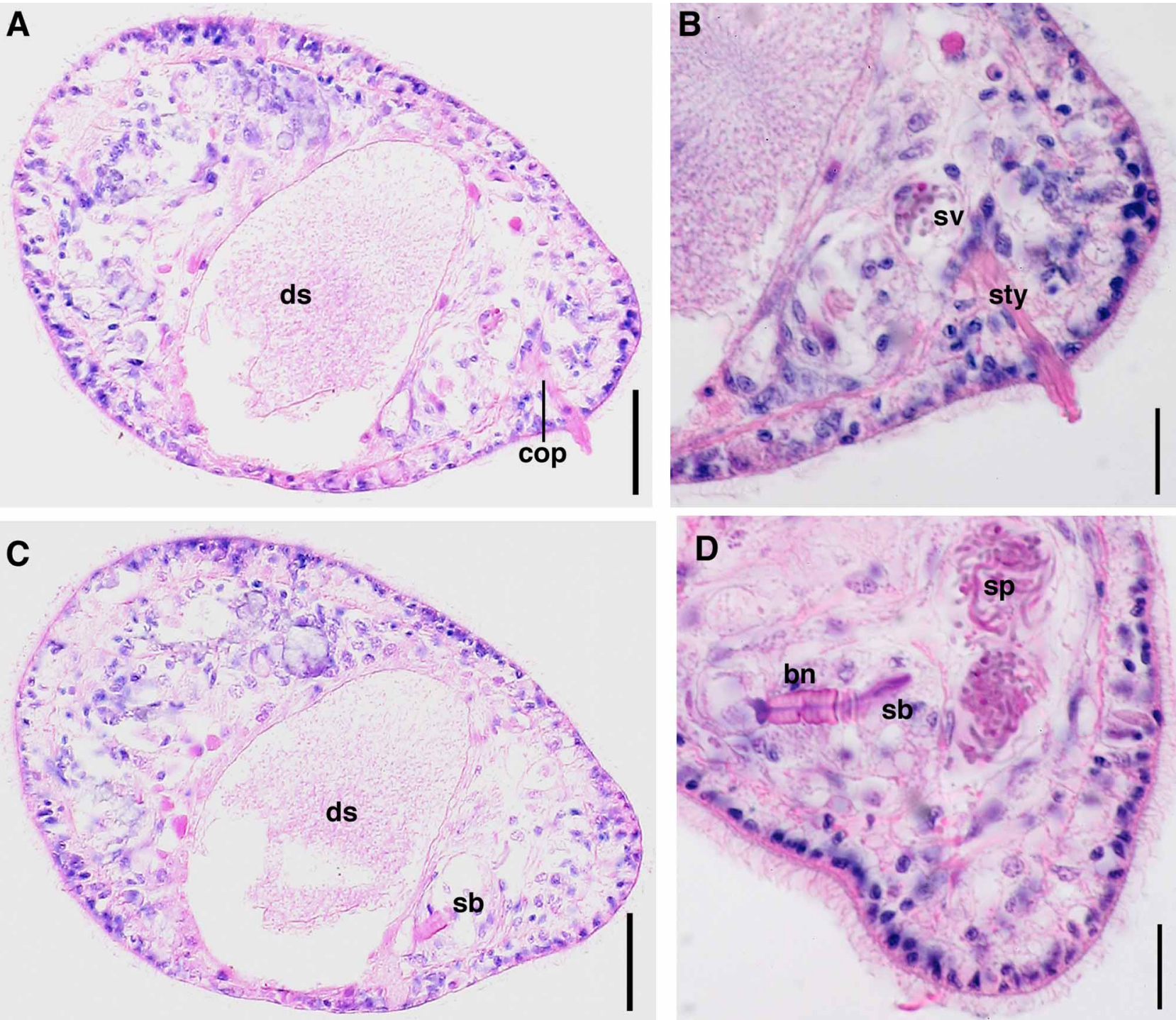

FIGURE 5. Philactinoposthia ischiae sp.nov. Photomicrographs of sagittal histological sections stained with hematoxylineosin. A. Section through length of body. Scale bar: $80 \mu \mathrm{m}$. B. Section through posterior. Scale bar: $40 \mu \mathrm{m}$. C. Section through length of body. Scale bar: $50 \mu \mathrm{m}$. D. Section through posterior. Scale bar: $50 \mu \mathrm{m}$. 
Ovaries paired, ventral; each lateral band with up to 7 oocytes, extending from middle of body to bursal nozzle, U50 to U80 (Fig. 4A). No female gonopore detected. Well-developed seminal bursa, at U85, with well-defined $\sim 18$ $\mu \mathrm{m}$ long bursal nozzle directed ventrally to the anterior (Fig. 4AB, 5CD). Testes paired, dorsal; separate from ovary. Testes extend anterior from middle of body to copulatory organ, from U40 to U80. Male gonopore positioned sub-terminally slightly lateral in dorsal view, opens directly to male copulatory organ composed of a long, $\sim 100 \mu \mathrm{m}$, curved, conical sclerotized stylet-like structure (Fig. 4AB, 5AB). Stylet needles strongly stained by eosin (Fig. 5B).
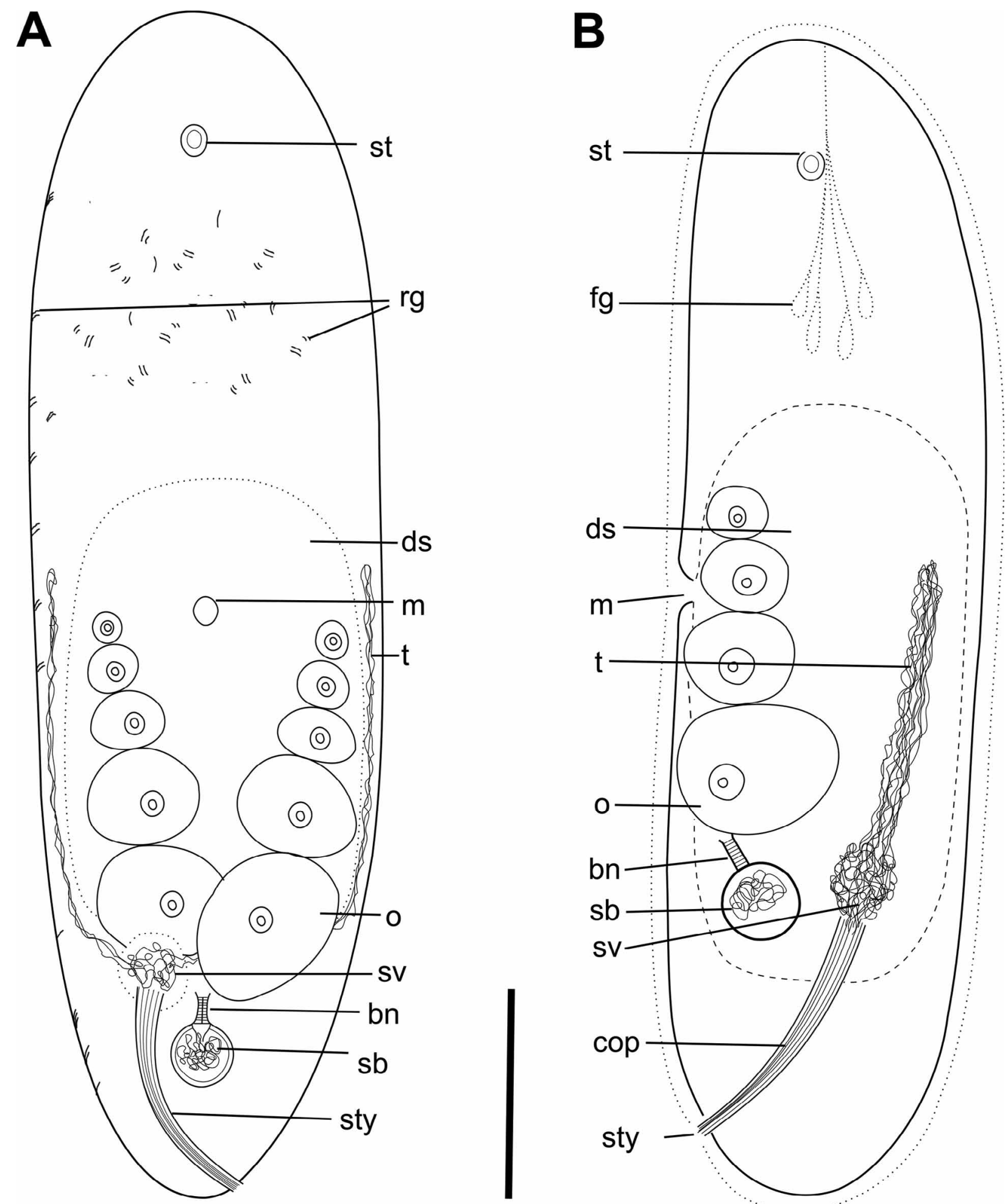

FIGURE 6. Philactinoposthia ischiae sp.nov. Reconstructions show arrangement of organs. A. Dorsal reconstruction of whole living animal. B. Sagittal reconstruction of the whole animal. Scale bar: $90 \mu \mathrm{m}$. 


\section{Philactinoposthia multipunctata sp.nov.}

(Figs. 3, 7, 8, 9)

Type material: Holotype: SMNH Type-8046. Paratype 1: SMNH Type-8047, Paratype 2: SMNH Type-8048.
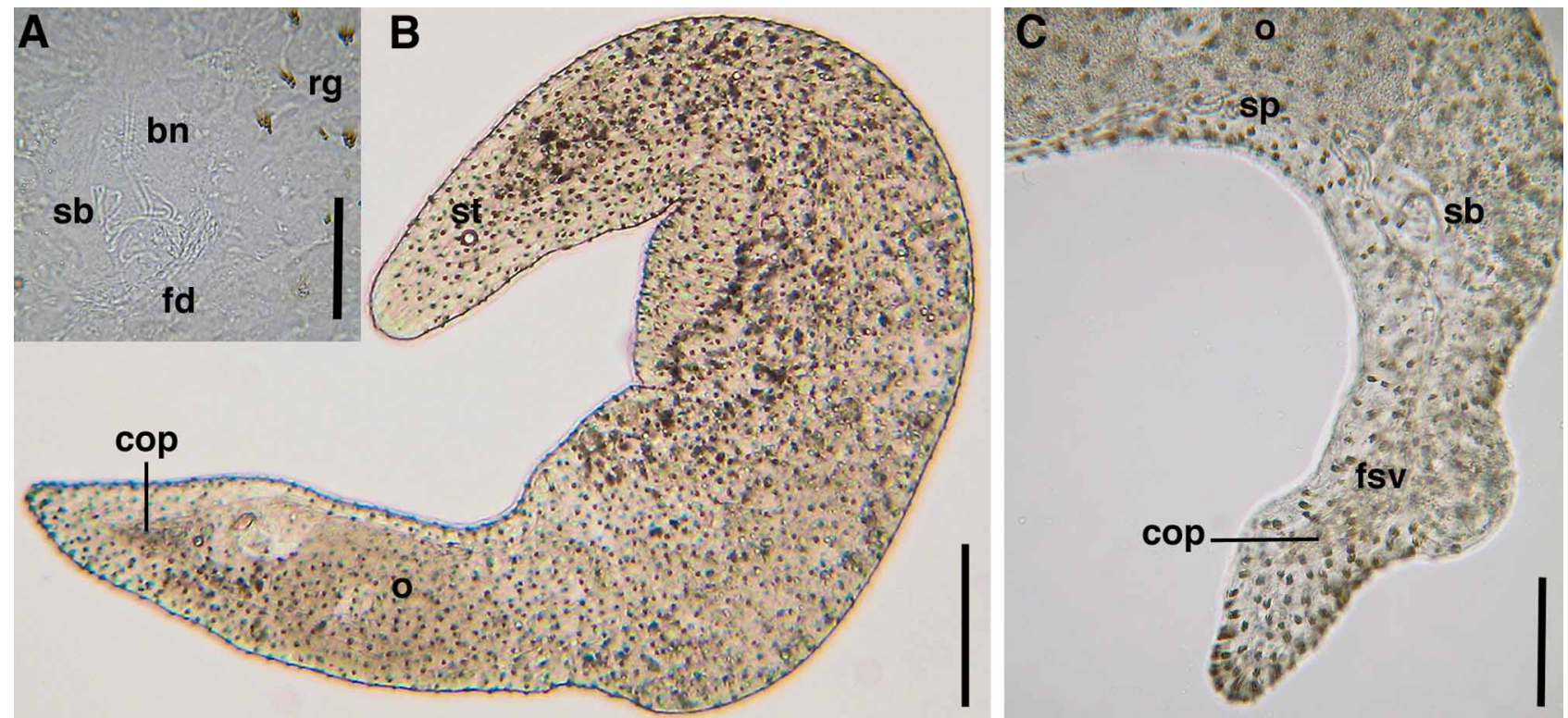

FIGURE 7. Philactinoposthia multipunctata sp.nov. Photomicrographs of living specimens. A. Dorsal view of whole squeezed specimen. Scale bar: $300 \mu \mathrm{m}$. B. View of posterior part of body. Scale bar: $90 \mu \mathrm{m}$. C. Female copulatory organ and rhabdoid glands. Scale bar: $110 \mu \mathrm{m}$.
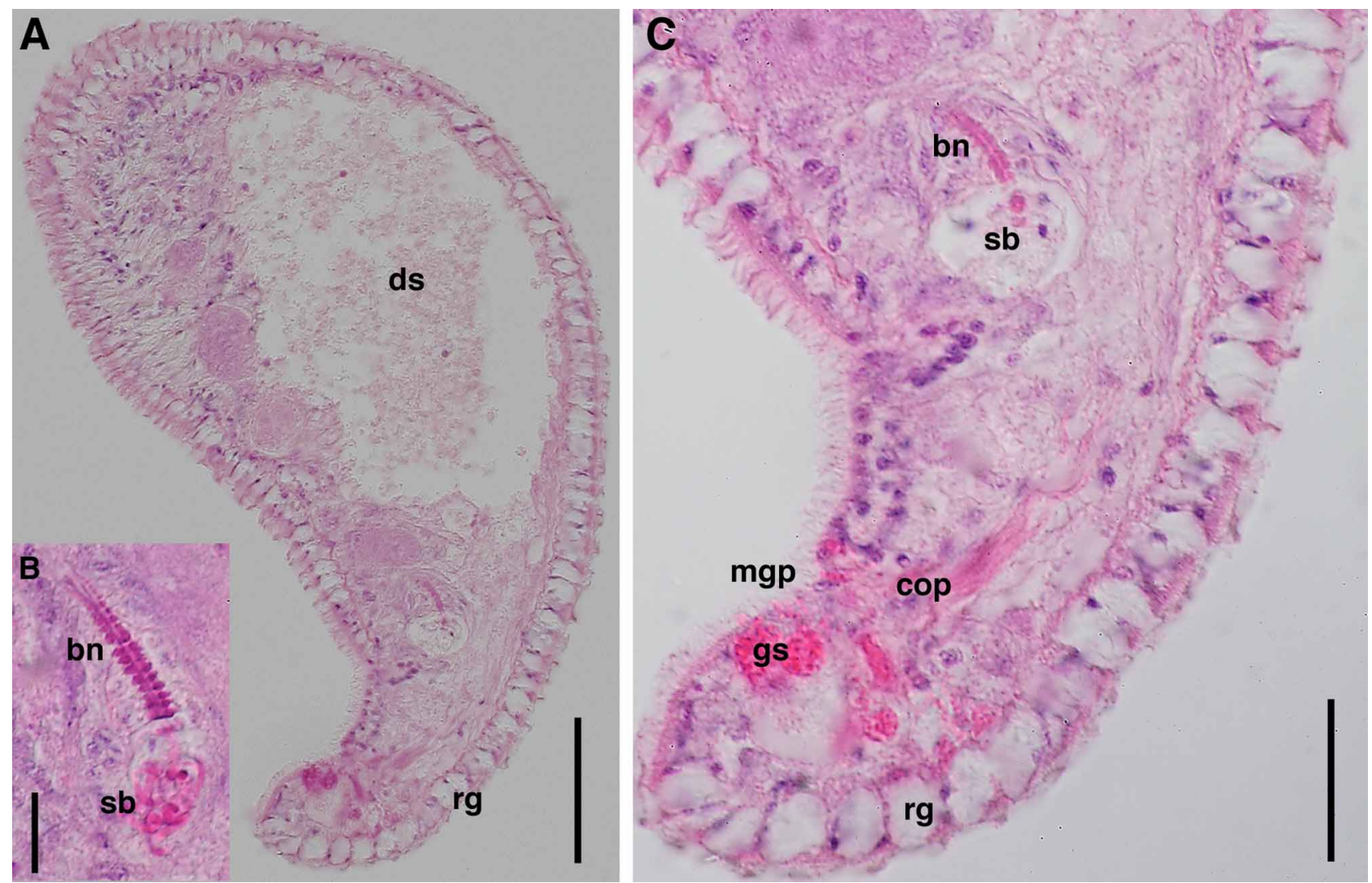

FIGURE 8. Philactinoposthia multipunctata sp.nov. Photomicrographs of sagittal histological sections stained with hematoxylin-eosin. A. Section through body. Scale bar: $350 \mu \mathrm{m}$. B. Female copulatory organ. Scale bar: $30 \mu \mathrm{m}$. C. Section through posterior. Scale bar: $100 \mu \mathrm{m}$. 

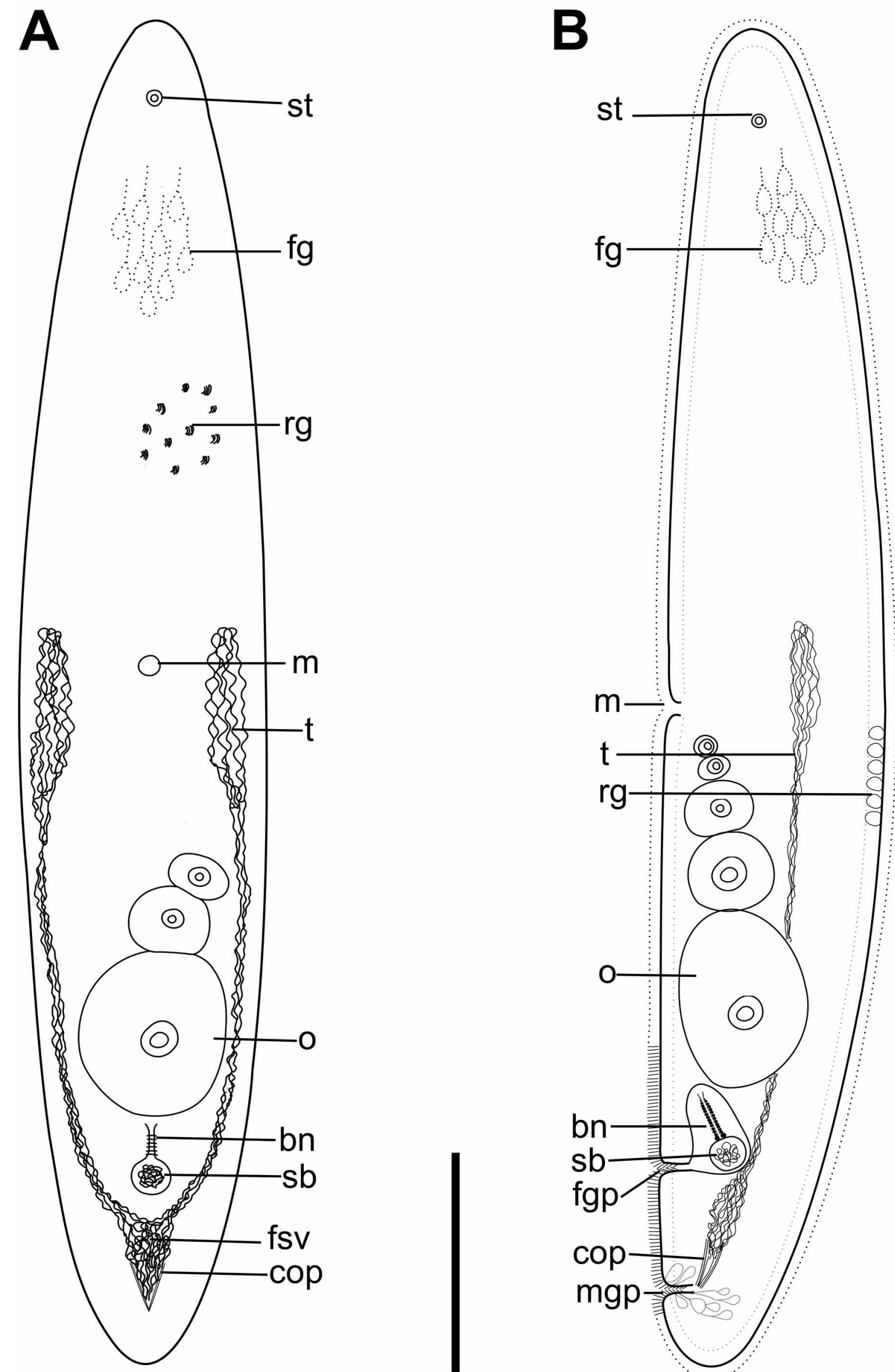

FIGURE 9. Philactinoposthia multipunctata sp.nov. Reconstructions show arrangement of organs. A. Dorsal reconstruction of whole living animal. B. Sagittal reconstruction of the whole animal. Scale bar: $500 \mu \mathrm{m}$. 
Type locality. Punta Ala Torre Balbo in Italy $\left(42^{\circ} 48^{\prime} 25^{\prime \prime} \mathrm{N}, 10^{\circ} 44^{\prime} 34^{\prime \prime} \mathrm{E}\right)$, at $3 \mathrm{~m}$ water depth in fine sand.

Other material examined. Living specimens in squeeze preparations; 1 set of $4-5 \mu \mathrm{m}$ serial sagittal sections of paraffin-embedded specimen.

Etymology. Name refers to the numerous rhabdoid glands. Multi $=$ many, punctum $=$ dot, in latin .

Description. Active and fast swimmer. Living specimens $\sim 3 \mathrm{~mm}$ long and $\sim 340-500 \mu \mathrm{m}$ wide. Body shape cylindric, both ends tapering. Epidermis completely covered with $5 \mu \mathrm{m}$ long cilia. Numerous red-colored rhabdoid glands in body wall, uniformly scattered across body (Fig. 7BC). Each rhabdoid gland with up to 9 strokes and 10 $\mu \mathrm{m}$ long (Fig. 7A). Epidermis uncolored in transmitted light. Statocyst $8 \mu \mathrm{m}$ in diameter, located anteriorly at level U7,5. Frontal organ well developed, cell bodies of frontal glands located posterior to statocyst, extending from U10 to U20. Mouth ventral, located in middle of body. Digestive central syncytium extends from U25 to U70.

Ovary unpaired, ventral, with up to 5 oocytes, extends posterior from level of testes, to bursal nozzle, U55-60 to U80. Female gonopore ventral, at level U85, opens directly to seminal bursa with wall and a fibrous disc in distal end; visible in pressed specimens (Fig. 7A). Seminal bursa connects anteriorly to well defined and clearly visible bursal nozzle with appearance like a stack of hats, with ventro-anterior direction (Fig. 8ABC). Bursal nozzle is long and slender, $60 \mu \mathrm{m}$ long and consists of at least 13 "hats".

Testes paired, lateral to ovary, extends anteriorly from level of mouth, to male copulatory organ posteriorly, U45 to U90. Male gonopore positioned in posterior end, ventral, at level U95, opens to male copulatory organ with $\mathrm{v}$-shaped sclerotized penis-like structure built of $100 \mu \mathrm{m}$ long stylet needles. Penis-like structure filled with spermatozoa, easily detected with moderate pressure. Needles weakly stained by eosin. Eosinophilic glands surround male antrum (Fig. 8C). False seminal vesicle located at proximal end of stylet-like structure.

\section{Philactinoposthia novaecaledoniae sp.nov.}

(Figs. 3, 10, 11, 12)

Type Material: Holotype: SMNH Type-8055. Paratype 1: SMNH Type-8056, Paratype 2: SMNH Type-8057.

Type Locality. Poe beach outside inner coral reef, New Caledonia, (21 $\left.37^{\prime} 31^{\prime \prime} \mathrm{S}, 165^{\circ} 23^{\prime} 47^{\prime \prime} \mathrm{E}\right)$, at $1.5 \mathrm{~m}$ water depth in clean fine sand, and Amedée Island, $\left(22^{\circ} 28^{\prime} 40^{\prime \prime} \mathrm{S}, 166^{\circ} 28^{\prime} 22^{\prime \prime} \mathrm{E}\right)$, at $15 \mathrm{~m}$ water depth in fine sand.

Other Material examined. Living specimens in squeeze preparations; 7 sets of $4-5 \mu \mathrm{m}$ serial sagittal sections of paraffin-embedded specimens.
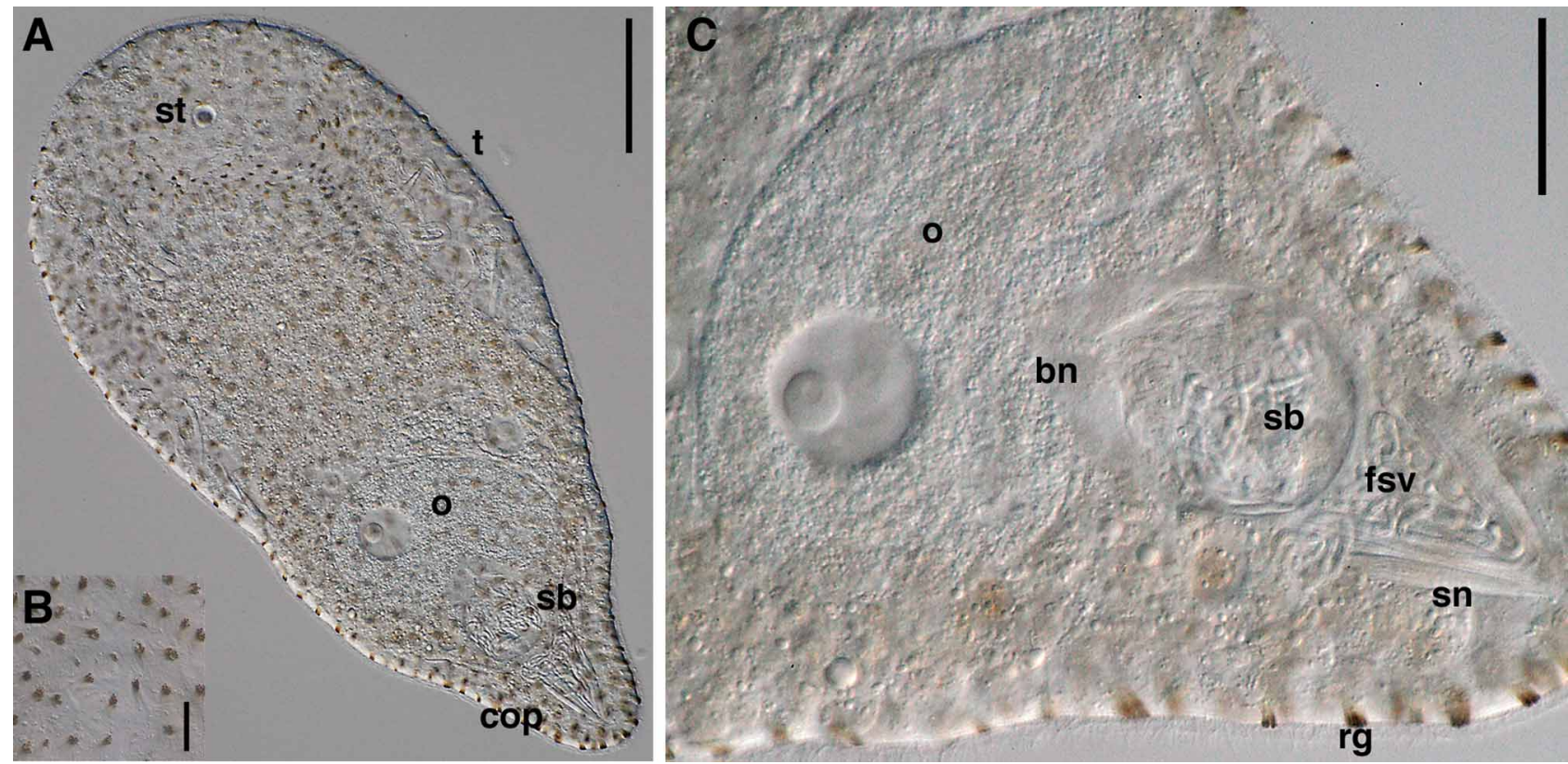

FIGURE 10. Philactinoposthia novaecaledoniae sp.nov. Photomicrographs of living specimens. A. Dorsal view of whole squeezed specimen. Scale bar: $80 \mu \mathrm{m}$. B. View of posterior part of body. Scale bar: $15 \mu \mathrm{m}$. C. Rhabdoid glands. Scale bar: 10 $\mu \mathrm{m}$. 
Etymology. The species epithet refers to the type locality, Nova Caledonia = New Caledonia in Latin.

Description. Living specimens $500-600 \mu \mathrm{m}$ long and $\sim 130 \mu \mathrm{m}$ wide ( $\mathrm{L} / \mathrm{W}=4)$. Sectioned specimens contracted, $200 \mu \mathrm{m}$ long and $100 \mu \mathrm{m}$ wide. Body shape cylindrical, both ends rounded bluntly. Epidermis completely covered with $5 \mu \mathrm{m}$ cilia. Numerous red to brown colored rhabdoid glands in body wall, scattered uniformly across body (Fig. 10AC). Each rhabdoid gland $15 \mu \mathrm{m}$ long with up to 12 strokes. Epidermis uncolored by transmitted light. Brownish coloration of digestive syncytium. Statocyst, 7,5 $\mu \mathrm{m}$ in diameter, located $25 \mu \mathrm{m}$ from anterior end in sections, at level U10. Frontal organ present, cell bodies of frontal organ located posterior to statocyst, extending from U11 to U20. Mouth ventral, located in anterior half of body, at level U55. Digestive central syncytium extends from level U25 to U60.

Ovary unpaired, ventral, with up to 3 oocytes, extending from posterior level of mouth to bursal nozzle, U60 to U80. Large ventro-median oocyte positioned close to bursal nozzle (Fig. 10C). Female gonopore slightly anterior to seminal vesicle, at U87, opens to globular and very distinct seminal bursa, about $30 \mu \mathrm{m}$ in diameter. Seminal bursa connects anteriorly to bursal nozzle. Bursal nozzle, $10 \mu \mathrm{m}$ long, small in relationship to the size of seminal bursa (Fig. 10C).
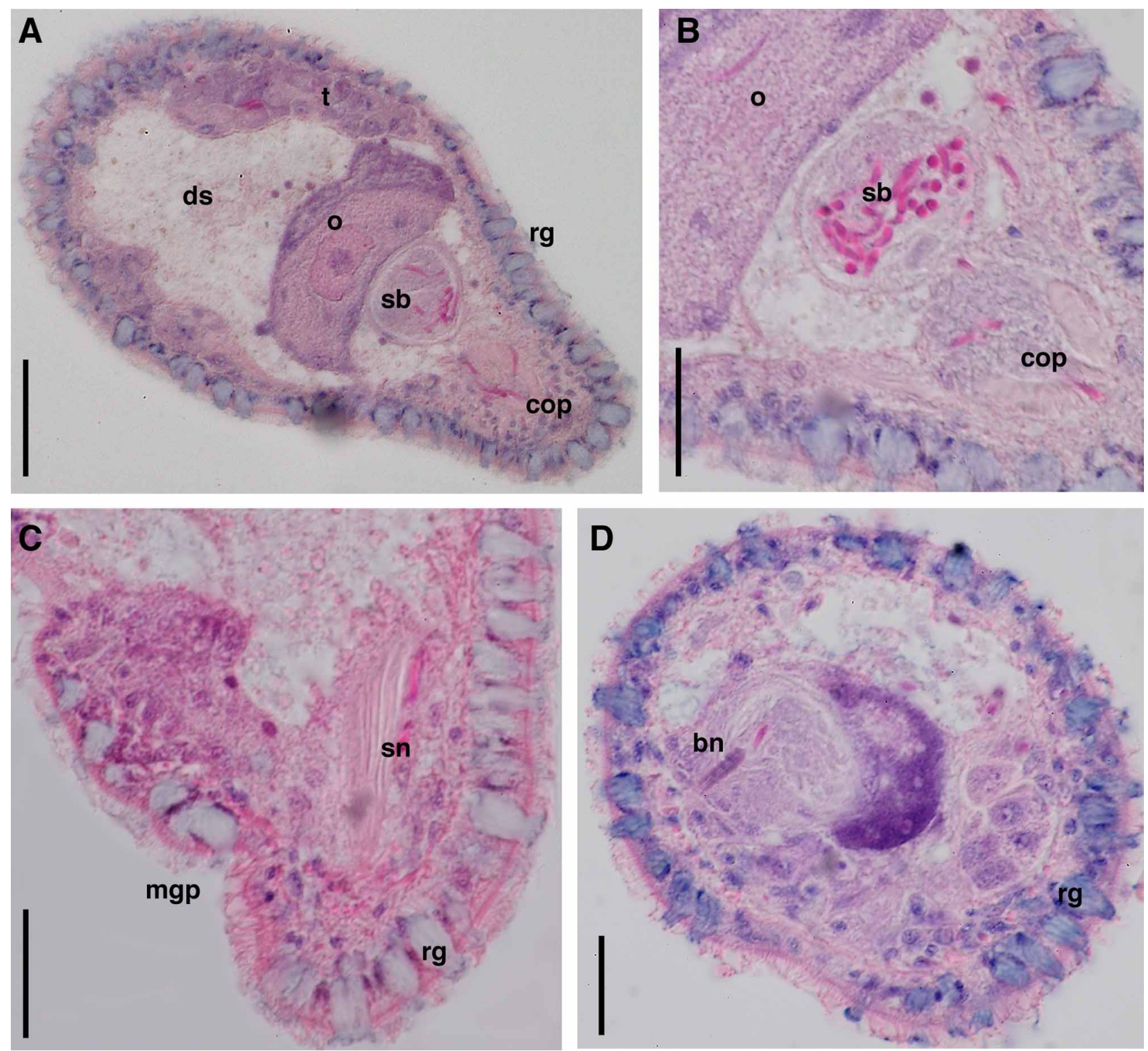

FIGURE 11. Philactinoposthia novaecaledoniae sp.nov. Photomicrographs of horizontal, sagittal and cross histological sections stained with hematoxylin-eosin. A. Horizontal section through body. Scale bar: $30 \mu \mathrm{m}$. B. Horizontal section through posterior. Scale bar: $15 \mu \mathrm{m}$. C. Sagittal section through posterior. Scale bar: $30 \mu \mathrm{m}$. D. Cross-section. Scale bar: $15 \mu \mathrm{m}$. 

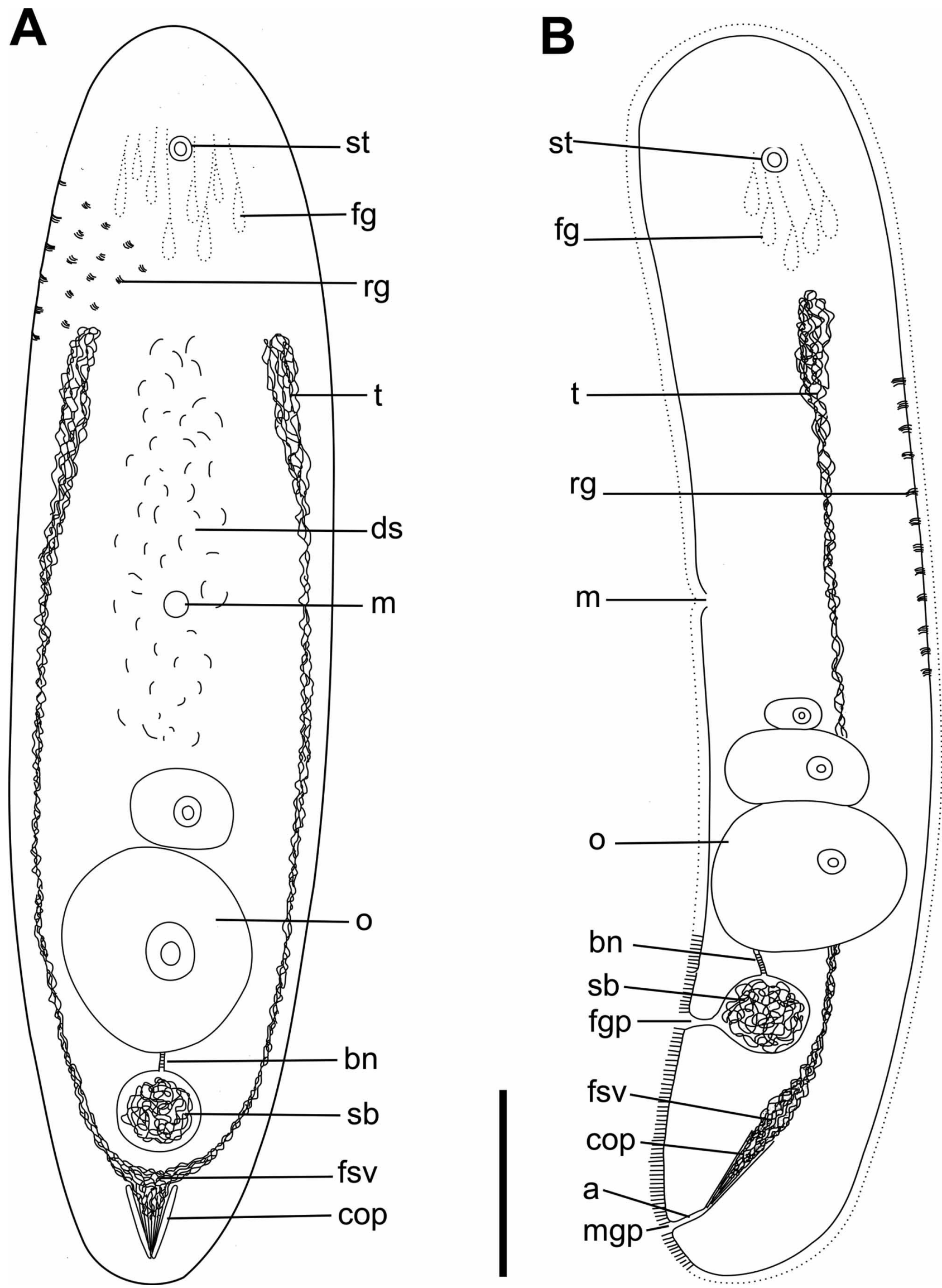

FIGURE 12. Philactinoposthia novaecaledoniae sp.nov. Reconstructions show arrangement of organs. A. Dorsal reconstruction of whole living animal. B. Sagittal reconstruction of the whole animal. Scale bar: $80 \mu \mathrm{m}$. 
Testes paired, lateral to ovary, extending from anterior to mouth, posteriorly to male copulatory organ, U25 to U90. Male gonopore subterminal on ventral side, at level U97, opens to male copulatory organ with sclerotized vshaped penis-like structure (Fig. 10AC). The characteristic v-shaped stylet consist of two groups containing a few needles each, $\sim 20 \mu \mathrm{m}$ long. Additional thin needles also present surrounded by spermatozoa. False seminal vesicle obscure, located at proximal end of penis-like structure, at U85.

Remarks. The presence of a male copulatory organ consisting of sclerotized stylets, which are not invaginated into the seminal vesicle, the "normal" arrangement of the body-wall musculture with distal cicular muscle fibres, and the abscence of any symbiotic algae identifies all four Philactinoposthia species as members of the family Actinoposthiidae. The female accessory organs, the well developed frontal glands and distinct rhabdoid glands identify them as members of Philactinoposthia. The Bayesian analysis of the combined 18S, $28 \mathrm{~S}$ and COI nucleotide data place $P$. brevis, $P$. ischiae and P. novaecaledoniae in a clade composed of Philactinoposthia species with maximum support (Fig. 3). P. multipunctata was not included in the phylogenetic analysis as there was no sequence data available for this species.

Philactinoposthia brevis sp.nov. can be distinguished from other species of the genus Philactinoposthia by its small arrow-shaped copulatory organ with at least four needles, $\sim 30 \mu \mathrm{m}$ long bursal nozzle with zigzag shape and ovary with one large oocyte visible in live specimens.

Philactinoposthia helgolandica Dörjes, 1968 is the most similar species, but has a longer and wider body (0.8-1 $\mathrm{mm}$ long, 0.1-0.2 mm wide) which is dorsoventrally flattened, denser teardrop-shaped dark green rhabdoid glands that together with dark grey coloration of the digestive parenchyma gives a characteristic pattern, subterminal male gonopore, larger copulatory organ in relationship to body size, penis-like structure centrally located inside the inner bladder (penis anchored in the proximal wall of the vesicle), testes extending to frontal glands, bursal nozzle without a zigzag shape and more numerous eggs.

P. brevis can appear similar to Microposthia listensis Faubel, 1974 due to the arrow-like copulatory organ, ovary with one large oocyte, similar body size and rhabdoid glands. However, P. brevis differs from M. listensis in having a seminal bursa with bursal nozzle, longer body in relationship to width and not a dorso-ventrally flattened body and smaller rhabdoid glands.

Paraproporus xanthus Marcus, 1950 has a similar combination of stylet and body size, but the copulatory organ is located terminally and a seminal bursa and bursal nozzle are absent.

Philactinoposthia ischiae sp.nov. can be distinguished from other Philactinoposthia species by its long curved posterior stylet (to the left from a dorsal view), male gonopore located subterminally slightly to the right, seminal vesicle at proximal end of stylet, well-defined bursal nozzle (thick in proportion to length), seminal bursa located at level of proximal part of stylet (i.e. not anterior to the stylet), paired ovary in posterior half of body, and the small uncolored rhabdoid glands that appear white in incident light. The rhabdoid glands were probably dissolved by the fixation and therefore not detectable in the sections. P. ischiae is similar to Philactinoposthia stylifera (Westblad, 1946) due to the curved stylet-like structure and the dorsal position of the seminal bursa. However, $P$. stylifera has larger rhabdoid glands $(20 \mu \mathrm{m})$, wider bursal nozzle with zig-zag appearance in sections, a female gonopore, and the ovary is more anterior. Philactinoposthia stylifera brasiliensis was reported by Hooge \& Rocha (2006) and classified by them as a subspecies of P. stylifera, although it differs from Westblad's description in the structure and size of rhabdoid glands, the absence of a female gonopore and a true seminal vesicle. The presence of a true seminal vesicle and the unpigmented digestive syncytium distinguishes $P$. ischiae from $P$. stylifera brasiliensis. $P$. ischiae can appear similar to Philocelis robrochai Hooge \& Rocha, 2006, but the position of the stylet, which is more curved and shorter, is different as it reaches the posterior end in $P$. ischiae but not in P. robrochai. The bursal nozzle in $P$. ischiae is directed dorsally to the anterior rather than dorsally slightly to the posterior. Rhabdoid glands are scattered across the body rather than positioned in distinct rows. As in other species currently classified in Philocelis Dörjes, 1968 , the vagina in $P$. robrochai is posterior to the male copulatory organ.

P. ischiae groups within a clade consisting of five Philactinoposthia species in the Bayesian analysis of the nucleotide dataset. A sister group relationship between the Philactinoposthia clade and a clade composed of four Philocelis species + Philactinoposthia saliens (Graff, 1882) + Daku woorimensis Hooge, 2003 is supported by the Bayesian analysis (Fig. 3). It should be noted that several species of Philactinoposthia have male copulatory organs with sclerotized elements similar to those in Philocelis.

This species was only found in sand from the volcanic carbon dioxide vents. Samples from outside the vent area contained no specimens. 
Philactinoposthia multipunctata sp.nov. is similar to Philactinoposthia coneyi Hooge \& Rocha, 2006, that shares with $P$. multipunctata an unpaired ovary, paired testes, red-colored rhabdoid glands and long and slender body shape. P. multipunctata is distinguished from other species of Philactinoposthia by its large body size with tapering ends, numerous red-colored rhabdoid glands, seminal bursa with fibrous disc in distal end, long and slender bursal nozzle with stack of hats appearance, $\mathrm{v}$-shaped sclerotized penis-like structure filled with spermatozoa.

The body length of $P$. multipunctata is $2-3 \mathrm{~mm}$, which is at least the double of $P$. coneyi, which is $700 \mu \mathrm{m}$. Body proportions are also different, $P$. coneyi is longer in relationship to its width compared to $P$. multipunctata (8:1, 6:1). Furthermore, $P$. coneyi has a rounded posterior end with vacuole, while P. multipunctata has a tapering posterior end without a vacuole.

The bursal nozzle in $P$. multipunctata is longer ( 13 "hats", $60 \mu \mathrm{m}$ long) and with less distinctive "stack of hats" than $P$. coneyi; especially discernible in sections. $P$. coneyi has a more muscular seminal vesicle with wellaligned sperm, shorter penis-like structure and not as numerous rhabdoid glands.

Philactinoposthia novaecaledoniae sp.nov. is distinguished from other Philactinoposthia species by its large seminal bursa in relation to body size (30 $\mu \mathrm{m}$ in diameter), the small bursal nozzle (10 $\mu \mathrm{m}$ long), and the posterior large copulatory organ (in relation to body size) with sclerotized elements forming a V-shaped stylet. P. novaecaledoniae can appear similar to $P$. viridorhabditis, $P$. helgolandica and $P$. coneyi due to unpaired ovaries, seminal bursa with bursal nozzle, posterior male copulatory organ and similar rhabdoid glands. $P$. novaecaledoniae has red to brown rhabdoid glands and a dark digestive syncytium whereas $P$. viridorhabditis is unpigmented with green-brown rhabdoid glands forming a species-specific pattern. The number of rhabdoid glands in $P$. novaecaledoniae is also higher than in P. viridorhabditis. Furthermore, the testes in P. viridorhabditis only extend anteriorly to the mid-body, the seminal vesicle is more massive, distinctive and separated from the male copulatory organ and the bursal nozzle is larger $(\sim 25 \mu \mathrm{m})$ than in P. novaecaledoniae. P. helgolandica has dark-green colored rhabdoid glands with dark grey coloration of digestive parenchyma, and much more massive seminal vesicle with well-aligned sperm and not as distinct stylet needles surrounded by seminal vesicle. $P$. coneyi is much longer in relation to body width, has a vacuole posteroterminally, shorter penis-like structure, more massive and muscular seminal vesicle and a welldefined bursal nozzle with the appearance of a stack of hats.

\section{Family Childiidae Dörjes, 1968 \\ Genus Childia Graff, 1910 \\ Childia aculifera sp.nov.}

(Figs. 13, 14, 15)

Type Material: Holotype: SMNH Type-8060. Paratype 1: SMNH Type-8061, Paratype 2: SMNH Type-8062.

Type Locality. Baye des Citrones in New Caledonia, $\left(22^{\circ} 17^{\prime} 44^{\prime \prime} \mathrm{S}, 166^{\circ} 26^{\prime} 11^{\prime \prime} \mathrm{E}\right)$, at $1 \mathrm{~m}$ water depth in fine sand. One specimen found in Amadée Island, $15 \mathrm{~m}$ water depth in fine sand, $\left(22^{\circ} 28^{\prime} 40^{\prime \prime} \mathrm{S}, 166^{\circ} 28^{\prime} 22^{\prime \prime} \mathrm{E}\right)$.

Other Material examined. Living specimens in squeeze preparations; 4 sets of $4-5 \mu \mathrm{m}$ serial sagittal sections of paraffin-embedded immature specimen.

Etymology. Name refers to the needle-like inclusions; acicula = small acus (needle); fera is from fero $=$ to carry; latin.

Description. Mature specimens up to $1,5 \mathrm{~mm}$ long and $\sim 350 \mu \mathrm{m}$ wide. Body shape cylindric and elongate, posterior end tapering and anterior end rounded. Body widest at level of the ovaries. Warm yellow to orange pigmentation scattered across body, more intense in middle of body (Fig. 13A). Epidermis completely ciliated with 5 $\mu \mathrm{m}$ long cilia. Frontal organ present, cell bodies of frontal organ extend from U10 to U20. Statocyst 7,5 $\mu \mathrm{m}$ in diameter, located $150 \mu \mathrm{m}$ from anterior end, at U10. Eosinophilic glands numerous, scattered throughout body. Mouth ventrally located in middle of body, at U50.

Body-wall musculature reversed, longitudinal muscles located outside circular muscles.

Paired ventral ovaries (Fig. 13C), each lateral band with up to seven oocytes. Ovary extends anterior to level of mouth and posteriorly to level of bursa, U55 to U85. Globular seminal bursa with wall, at level U85. Female gonopore ciliated, positioned on ventral side, at level of seminal bursa, U85. 

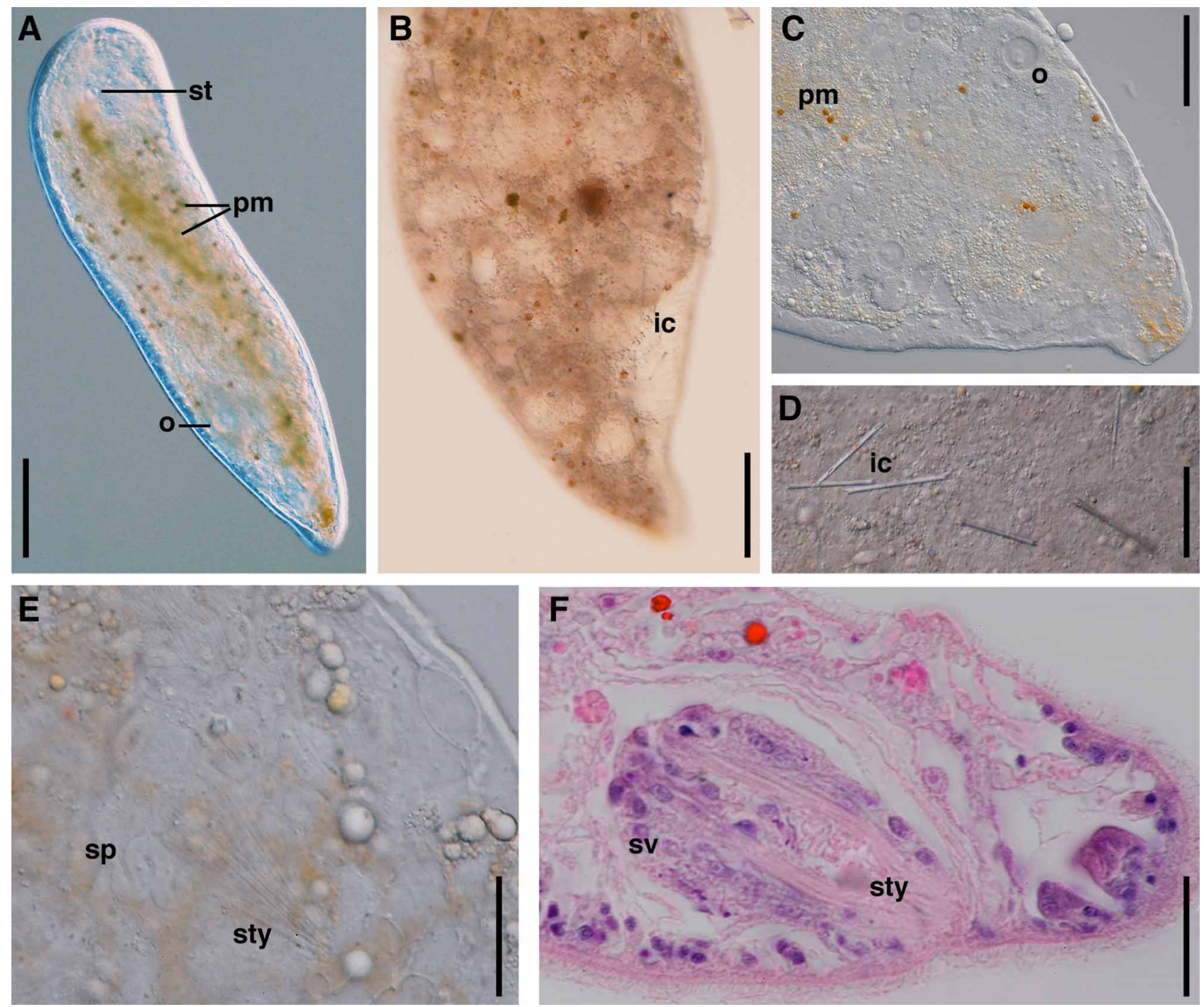

FIGURE 13. Childia aculifera sp.nov. A-E photomicrographs of living specimens. A. Dorsal view of whole specimen. Scale bar: $250 \mu \mathrm{m}$. B. View of posterior part of body. Scale bar: $100 \mu \mathrm{m}$. C. View of posterior end. Scale bar: $75 \mu \mathrm{m}$. D. Inclusions (arrowhead). Scale bar: $30 \mu \mathrm{m}$. E. View of posterior part of body. Scale bar: $40 \mu \mathrm{m}$. F. Photomicrograph of sagittal histological sections stained with hematoxylin-eosin. Scale bar: $30 \mu \mathrm{m}$.

Testes paired, lateral to ovaries, extending anteriorly to level of ovaries and posteriorly to male copulatory organ, from level U55 to U90. Ventral male gonopore posteriorly at level U95. Opens immediately to male copulatory organ, with conical stylet-like structure, composed of tightly packed sclerotized needles (Fig. 13EF). Individual needles of copulatory structure radiating at the proximal end of the stylet. In pressed live specimens one can detect about 17 needles, up to $50 \mu \mathrm{m}$ long. Needles weakly stained by eosin. Stylet canal large and filled with sperm, discernible in sections. Seminal vesicle surrounding stylet-like structure.

Long and thin needle-like inclusions present, $28-30 \mu \mathrm{m}$ long and $2 \mu \mathrm{m}$ wide, reflective and shiny in transmitted and reflected light (Fig. 13BD). Inclusions scattered across body, but missing in anterior part of body, extending from U15 to U100. Inclusions visible with dissecting microscope in living specimens. 

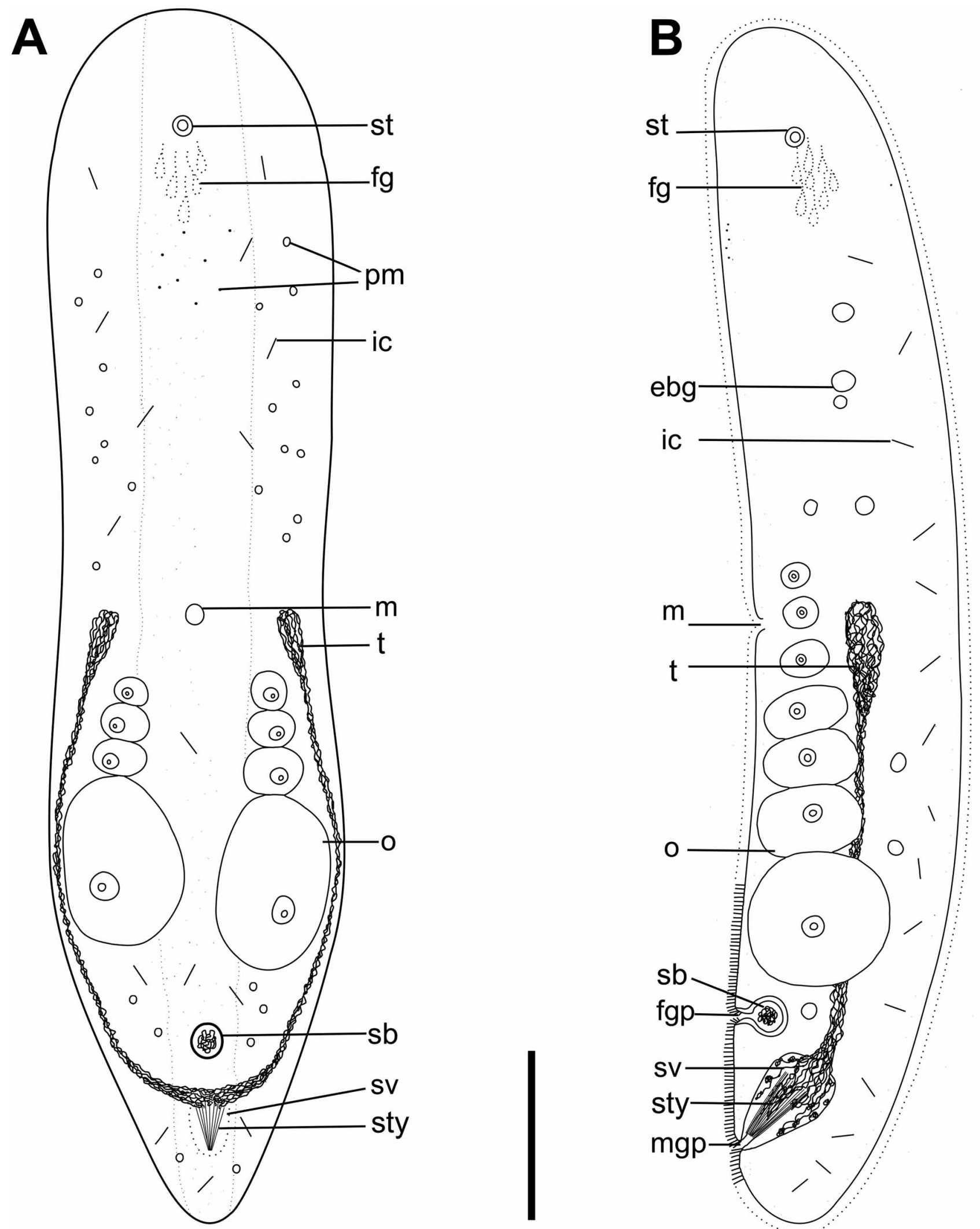

FIGURE 14. Childia aculifera sp.nov. Reconstructions show arrangement of organs. A. Dorsal reconstruction of whole living animal. B. Sagittal reconstruction of the whole animal. Scale bar: $220 \mu \mathrm{m}$. 


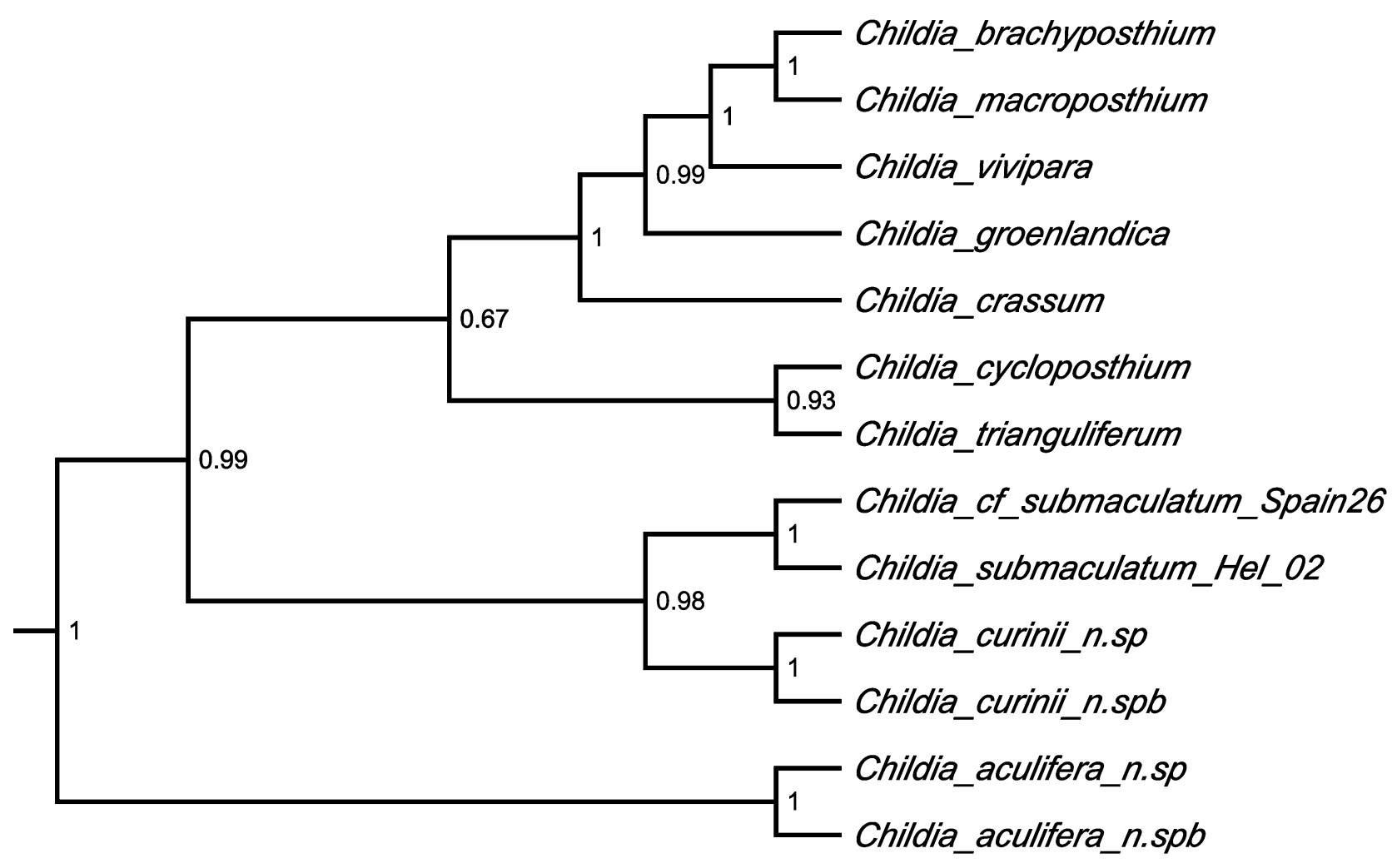

FIGURE 15. Detail from the majority rule consensus tree summarizing the result of the Bayesian analysis of the combined $18 \mathrm{~S}$ rDNA, 28S rDNA and COI dataset with the GTR+G substitution model after 10 million generations sampled every 1000 generations after a burnin of 5 million generations. C. aculifera is placed as the sister to all other Childia species. Childia curinii is placed as the sister species of the two cryptic species identified as $C$. submaculatum.

Childia curinii sp. nov.

(Figs. 15, 16, 17, 18)

Type Material: Holotype: SMNH Type-8049. Paratype 1: SMNH Type-8050, Paratype 2: SMNH Type-8051.

Type Locality. Formica, Italy ( $\left.42^{\circ} 34^{\prime} 19^{\prime \prime} \mathrm{N}, 10^{\circ} 53^{\prime} 5^{\prime \prime} \mathrm{E}\right)$, from $37 \mathrm{~m}$ water depth, in fine sand.

Other Material examined. Living specimens in squeeze preparations; 3 sets of $4-5 \mu \mathrm{m}$ serial sagittal sections of paraffin-embedded specimen.

Etymology. Species name honors professor Marco Curini Galletti.

Description. Mature living specimens up to $3000 \mu \mathrm{m}$ long and $700 \mu \mathrm{m}$ wide. Body shape cylindric, elongate, widest anteriorly, ends rounded. Body with yellow to green pigment uniformly scattered across body (Fig. 16ABD). Epidermis completely ciliated with $5 \mu \mathrm{m}$ long cilia. Frontal organ well developed. Cell bodies of frontal organ located in the anterior $1 / 4$ of body. Subdermal eosinophilic glands present, sparsely scattered throughout body. Statocyst located $250 \mu \mathrm{m}$ from anterior end, at U10, $5 \mu \mathrm{m}$ in diameter. Mouth ventral, at U35.

Body-wall musculature reversed, longitudinal muscles located outside the circular muscles (Fig. 17B).

Paired ovaries, each lateral band with up to twelve oocytes, ventral - discernible in sectioned material and partially in live specimens. Ovaries extend anterior to level of mouth and posteriorly to seminal bursa, from U35 to U75. Globular seminal bursa present, at U75, with well-developed bursal wall (Fig. 17B). Ciliated female gonopore positioned on ventral side, at level of seminal bursa.

Testes paired, compact, lateral to ovaries, extending anteriorly to level of mouth and posteriorly to male copulatory organ, from U30 to U83. Male gonopore positioned posteriorly on ventral side, U87. Opening immediately to male copulatory organ with sclerotized, conical stylet-like structure, composed of several tightly packed needles (Figs. 16C, 17AB). Individual needles of copulatory structure radiating at the proximal end of the stylet.

In squeezed live specimens one can detect about 25 needles up to $75 \mu \mathrm{m}$ long. Needles weakly stained by eosin. Stylet-like structure surrounded by seminal vesicle (Fig. 17AB). 
Curved rod-like inclusions present, $30 \mu \mathrm{m}$ long (up to $60 \mu \mathrm{m}$ in some cases), and 5-8 $\mu \mathrm{m}$ wide, scattered throughout body in parenchyma, but most visible in posterior (Fig. 16BC).
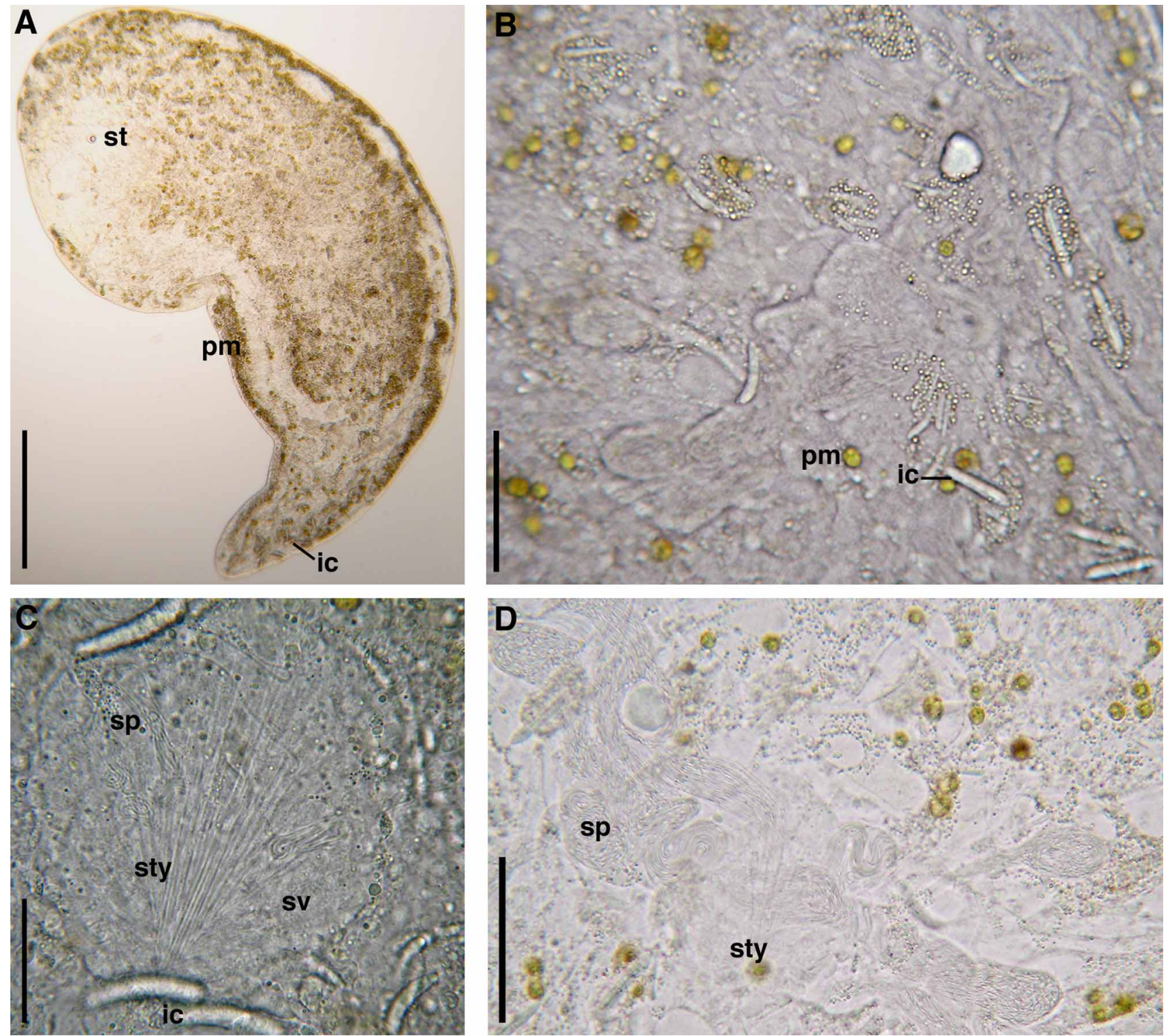

FIGURE 16. Childia curinii sp.nov. Photomicrographs of living specimens. A. Dorsal view of whole specimen. Scale bar: 500 $\mu \mathrm{m}$. B. View of mid-body. Scale bar: $60 \mu \mathrm{m}$. C. Male copulatory organ and inclusions. Scale bar: $30 \mu \mathrm{m}$. D. View of posterior end of body. Scale bar: $80 \mu \mathrm{m}$.

Remarks. The two Childia species can be identified as members of the monotypic Childiidae due to the well developed single copulatory organ built of tightly packed sclerotized needles and the body-wall musculature with longitudinal fibers positioned outside circular fibers. The Bayesian analysis of the nucleotide data places $C$. aculifera as sister to all other Childia species and Childia curinii is the sister species of the two cryptic species identified as C. submaculatum (Fig 15).

Childia aculifera sp.nov. is easily distinguished from other Childia species by its warm yellow to orange pigmentation, needle-like reflective inclusions, cone shaped stylet-structure with large stylet canal surrounded by seminal vesicle and numerous eosinophilic body glands.

Inclusions are also present in Childia curinii and Childia tranguliferum (Westblad, 1942), but with different size, shape and reflectiveness. Inclusions in $C$. trianguliferum are triangle-shaped and highly reflective. In $C$. 
curinii inclusions are rod-like, much larger (30-60 $\mu \mathrm{m}$ long and 5-8 $\mu \mathrm{m}$ wide), slightly curved and not particularly reflective, while in C. aculifera they are reflective, needle-like and much thinner $(2 \mu \mathrm{m}$ wide). Moreover, the styletlike structure in $C$. trianguliferum differs from $C$. aculifera in having a slightly curved distal end and more irregular-shaped and less compact needles. The mouth in $C$. trianguliferum is located in the anterior end, the seminal bursa is more dorsally positioned, the seminal vesicle does not surround the stylet-like structure and yellow pigmentation is absent. The stylet-like structure of C. aculifera is smaller $(50 \mu \mathrm{m})$, with fewer needles, than in $C$. curinii, $(75 \mu \mathrm{m})$. The female antrum is shorter in $C$. curinii and the stylet-like structure has a broader shape, compact, and without large stylet canal visible in sections. Both species have yellow pigmentation, but the color is more warm yellow to orange in $C$. aculifera and yellow to green in C. curinii. C. aculifera also has more intense pigmentation in the middle of body, whereas pigmentation in $C$. curinii is uniformly scattered across the body. In C. curinii testes extend further anteriorly and the mouth is located in anterior end of body. Furthermore, C. aculifera has less compact eggs, more numerous eosinophilic body glands, and a seminal bursa located closer to the stylet-like structure, than C. curinii and C. trianguliferum.
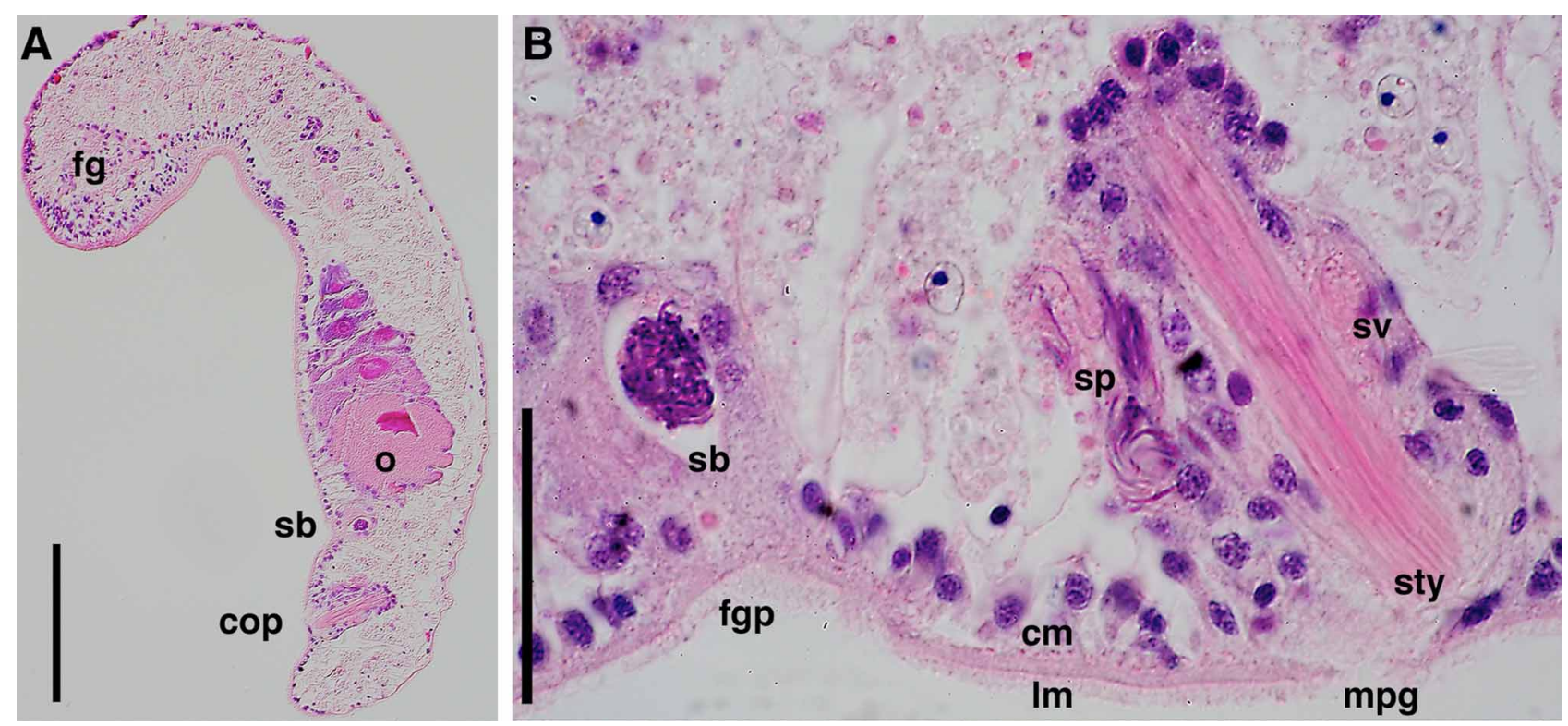

FIGURE 17. Childia curinii sp.nov. Photomicrographs of sagittal histological sections stained with hematoxylin-eosin. A. Section through length of body. Scale bar: $150 \mu \mathrm{m}$. B. Showing section through male and female copulatory organs and circular (double arrowhead) and longitudinal (arrowhead) muscles in body wall. Scale bar: $50 \mu \mathrm{m}$.

C. curinii is easily distinguished from other Childia species by its yellow pigmentation, rod-shaped inclusions in the parenchyma, broad cone-shaped stylet-like structure surrounded by the seminal vesicle and relatively large body size, $3 \mathrm{~mm}$. Inclusions are also present in Childia trianguliferum (Westblad, 1942) and Childia aculifera, but in $C$. trianguliferum they are triangular and in C. aculifera they are needle-like and reflective in transmitted and reflected light. The inclusions in Childia curinii are rod-shaped, much wider than the inclusions in C. aculifera and not particularly reflective. $C$. trianguliferum differs from $C$. curinii in having fewer and less compact visible needles in the stylet-like structure, more numerous and tightly packed eggs, and mouth located closer to statocyst at 25U. The stylet-like structure of $C$. curinii has more needles and is larger $(75 \mu \mathrm{m})$ than the stylet like structure in $C$. aculifera $(50 \mu \mathrm{m})$. The female antrum is shorter in $C$. curinii than in $C$. aculifera. Both species have yellow pigmentation, but the color is yellow to green in C. curinii and more warm yellow to orange in C. aculifera which also has more intense pigmentation in the middle of the body, whereas pigmentation in $C$. curinii is uniform. In $C$. curinii testes extend further anteriorly and the mouth is in the anterior end of the body whereas it is located in the mid-body in C. aculifera. C. curinii can appear similar to Childia crassum (Westblad, 1942) in sagittal sections and drawings because both have paired ovaries and testes, cone-shaped stylet-like copulatory structure, similar position of seminal bursa and large body size. However, there are no inclusions in C. crassum and the pigmentation is orange if present, not yellow. In C. curinii the bursal wall is of uniform thickness, whereas the anterior bursal wall is thicker in C. crassum. The stylet-like copulatory structure in C. curinii is somewhat similar to the stylet like 
structure in Childia submaculatum (Westblad, 1942), but smaller in relation to body size and is surrounded by the seminal vesicle. Live specimens of $C$. submaculatum are unpigmented, lack inclusions, and have a distinctive pattern formed by sub-epidermal glands that appear white in reflected and dark in transmitted light.
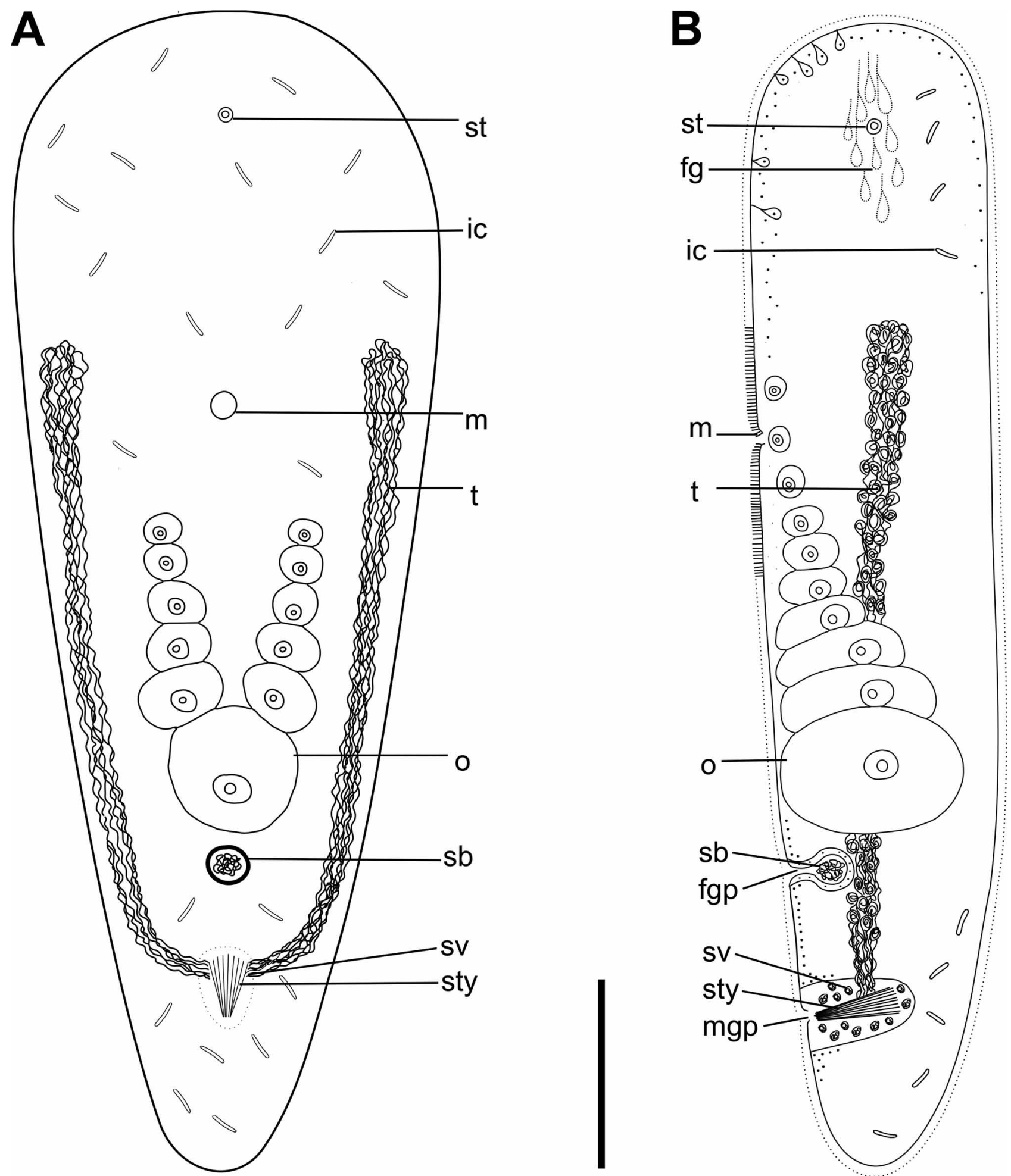

FIGURE 18. Childia curinii sp.nov. Reconstructions show arrangement of organs. A. Dorsal reconstruction of whole living animal. B. Sagittal reconstruction of the whole animal. Scale bar: $500 \mu \mathrm{m}$. 


\section{Family Isodiametridae Hooge \& Tyler, 2005 \\ Genus Pharyngia gen. nov.}

Diagnosis. Isodiametridae with a pharynx but without copulatory bursa or any other secondary female organs.

Type species. Pharyngia furva sp. nov.

Etymology. Genus epithet refers to the presence of pharynx.

\section{Pharyngia furva gen. et sp.nov.}

(Figs. 19, 20, 21, 22)

Type Material: Holotype: SMNH Type-8044. Paratype 1: SMNH Type-8045.

Type Locality. Eilat, $\left(29^{\circ} 30^{\prime} 27^{\prime \prime} \mathrm{N}, 34^{\circ} 56^{\prime} 16^{\prime \prime} \mathrm{E}\right)$, animals occurred at $20-25 \mathrm{~m}$ water depth in fine sand.

Other Material examined. Living specimens in squeeze preparations.

Etymology. Species name refers to the dark brown appearance of body, furva $=$ dark-colored in latin.

Description. Living specimens up to $2000 \mu \mathrm{m}$ long and $500 \mu \mathrm{m}$ wide (1/5). Body extremely fragile, therefore no anesthetization was used before fixation in Bouin. Specimens fixed for histological sectioning contracted. Body shape cylindrical, anterior end rounded, posterior part tapering (Fig. 19A). Epidermis uncolored and completely ciliated with $5 \mu \mathrm{m}$ long cilia. The margins of body are clear, the rest of body with dark brown coloration. Statocyst located $280 \mu \mathrm{m}$ from anterior end, at U12. Frontal organ present, cell bodies located at level of statocyst, extending from U10 to U20. Mouth opening on ventral surface in anterior end, slightly anterior to statocyst, at U10. Mouth opens to ciliated tube-shaped pharynx, extending from U10 to U22 (Fig. 20AB). In live specimens pharynx is difficult to see due to dark coloration of body. Digestive central syncytium diffuse.

Ovary unpaired, ventral, with up to 4 oocytes, extending from the posterior end of pharynx to middle of body, U58 to U30. In live specimens oocytes are dark brown and highly visible (Fig. 19AB). Seminal bursa or any other female accessory organs absent in all collected specimens.

Testes paired, lateral to ovary, compact, extend from posterior of pharynx to male copulatory organ, U28 to U60. Male gonopore positioned posterior to mid-ventral oocyte, at U65, and opens to $60 \mu \mathrm{m}$ long well-developed ciliated antrum followed by the male copulatory organ consisting of $15 \mu \mathrm{m}$ long penis-papilla weakly stained by eosin (Figs. 19B, 20AC).

Penis invaginated into muscular seminal vesicle, about $40 \mu \mathrm{m}$ in diameter, with well developed wall. Copulatory organ $55 \mu \mathrm{m}$ long and $48 \mu \mathrm{m}$ wide in total.

Remarks In the Bayesian analysis Pharyngia furva gen. et n.sp. is the first branch in a clade composed of all included Isodiametridae and some species currently classified in Actinoposthiidae and Haploposthiidae Westblad, 1948 (Fig 22). Hence, classifying it in one of the currently recognized genera would render that genus non-monophyletic. This species is therefore classified in the new genus Pharyngia within Isodiametridae on the basis of the male copulatory organ which has a penis invaginated into a muscular seminal vesicle.

Diagnosis. Pharyngia gen. nov. Isodiametridae with a pharynx but without copulatory bursa or any other secondary female organs.

There are only two previously known species in the family Isodiametridae that have a pharynx, Isodiametra helgolandica (Dörjes, 1968) and Praeaphanostoma longum Dörjes, 1968. However, in Isodiametra Hooge \& Tyler, 2005 there is a seminal bursa with a bursal nozzle and in Praeaphanostoma Dörjes 1968 there is a tubular copulatory organ and a seminal bursa. Faerlea glomerata Westblad, 1945 has a similar copulatory organ to the one in $P$. furva, but the penis is tubular instead of a small penis-papilla, the male antrum is much shorter, the animal is unpigmented and translucent and there is no pharynx.

P. furva can appear similar to Hallangia proporoides Westblad, 1946, however P. furva has a copulatory organ with penis-papilla, a long ciliated male antrum and the coloration of body is dark brown, while $H$. proporoides has a tube formed penis, a short male antrum and white to yellow coloration. Moreover, H. proporoides has a seminal bursa and the anterior end is somewhat pointed. Sequences of $H$. proporoides are included in the phylogenetic analysis and are more closely related to Hofstenia (Fig. 26). 

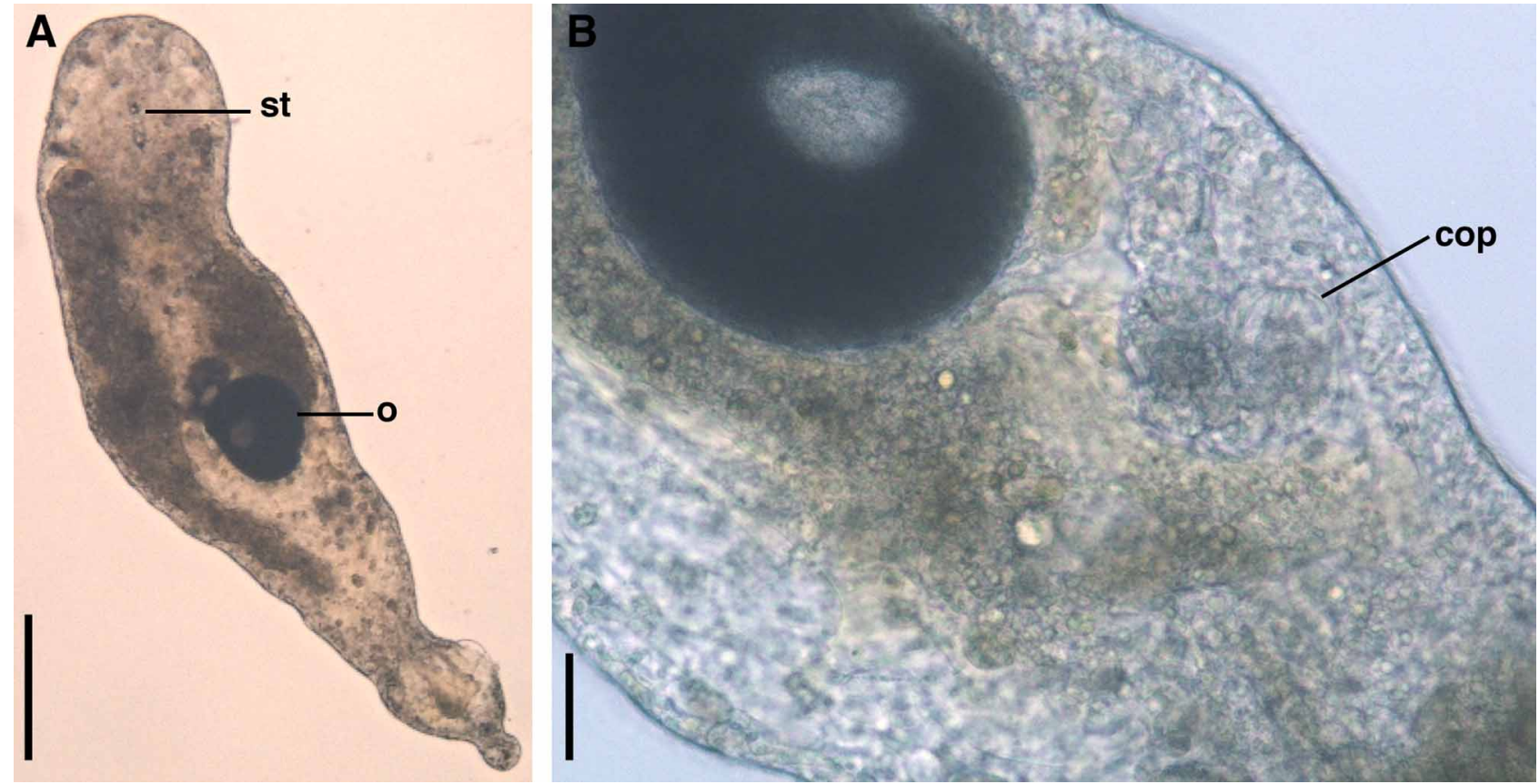

FIGURE 19. Pharyngia furva sp.nov. Photomicrographs of living specimens. A. Dorsal view of whole specimen. Scale bar: $320 \mu \mathrm{m}$. B. View of mid-body showing male copulatory organ. Scale bar: $100 \mu \mathrm{m}$.
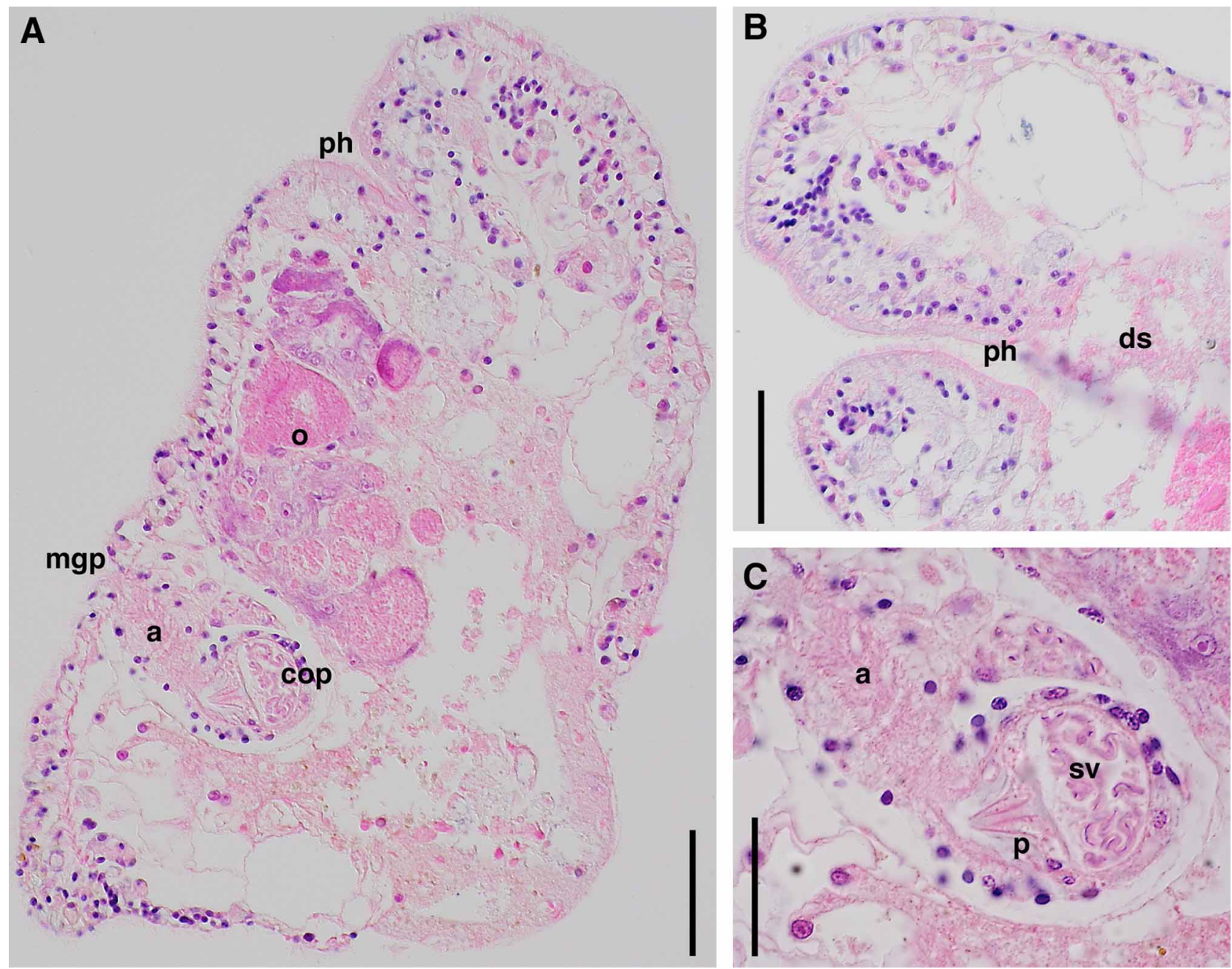

FIGURE 20. Pharyngia furva sp.nov. Photomicrographs of sagittal histological sections stained with hematoxylin-eosin. A. Section through length of body. Scale bar: $50 \mu \mathrm{m}$. C. Section through posterior. Scale bar: $20 \mu \mathrm{m}$. 

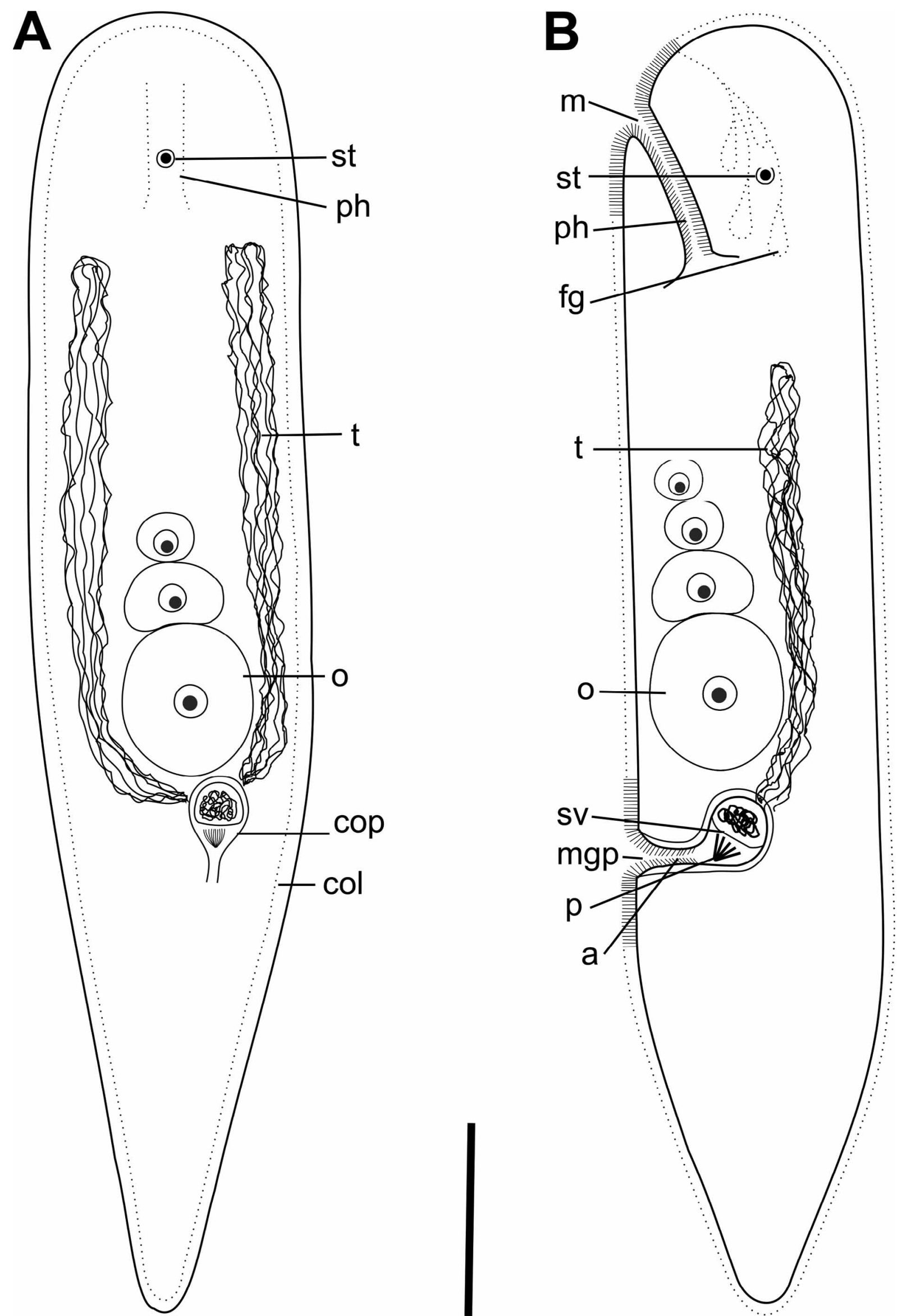

FIGURE 21. Pharyngia furva sp.nov. Reconstructions show arrangement of organs. A. Dorsal reconstruction of whole living animal. B. Sagittal reconstruction of the whole animal. Scale bar: $300 \mu \mathrm{m}$. 


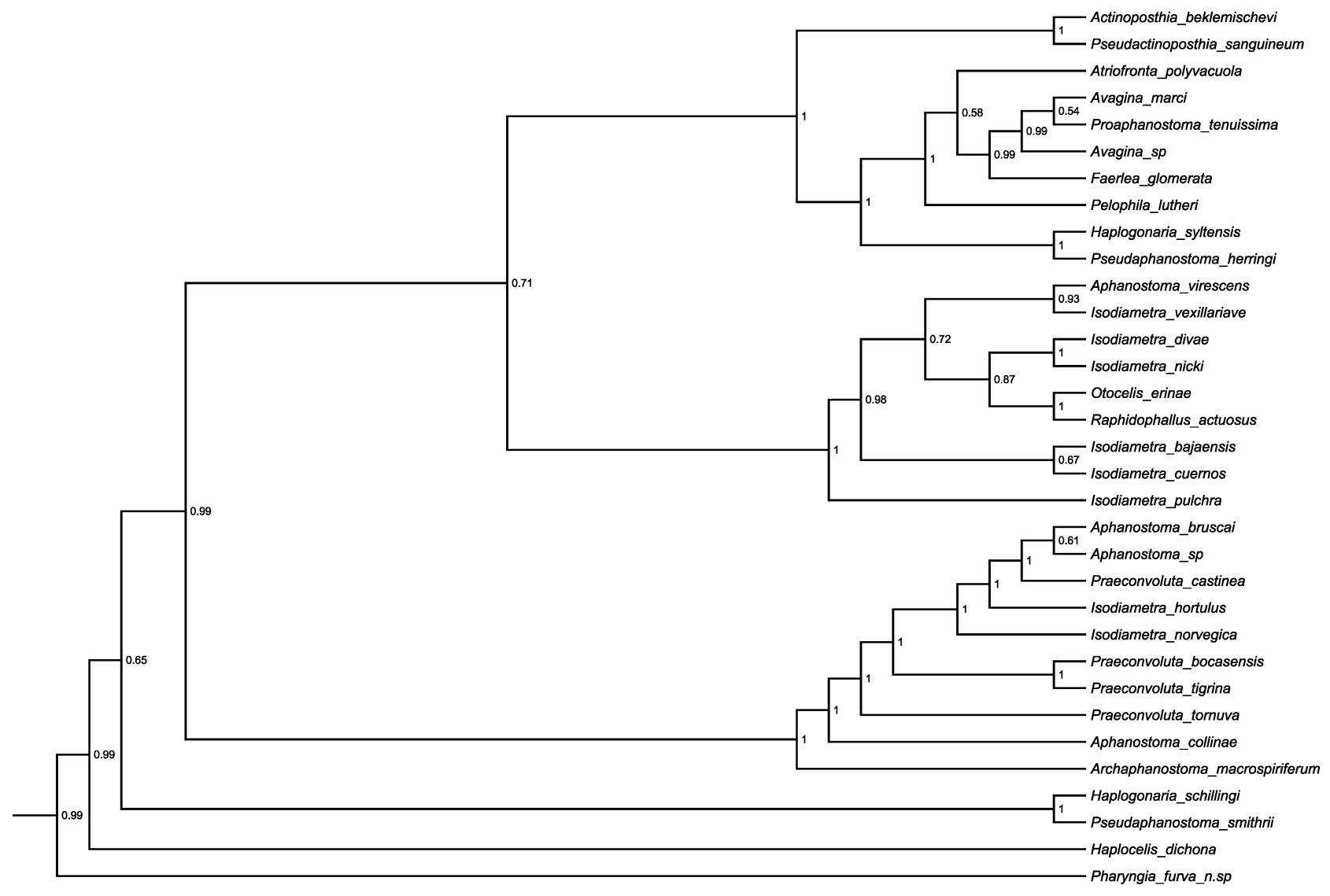

FIGURE 22. Detail from the majority rule consensus tree summarizing the result of the Bayesian analysis of the combined $18 \mathrm{~S}$ rDNA, 28S rDNA and COI dataset with the GTR+G substitution model after 10 million generations sampled every 1000 generations after a burnin of 5 million generations. Pharyngia furva gen. et $n$.sp. is the first branch in a clade composed of all included Isodiametridae and some species currently classified in Actinoposthiidae and Haploposthiidae.

Family Solenofilomorphidae Dörjes, 1968

Genus Solenofilomorpha Dörjes, 1968

Solenofilomorpha justinei sp.nov.

(Figs. 23, 24, 25, 26)

Type Material: Holotype: SMNH Type-8058. Paratype 1: SMNH Type-8059.

Type Locality. Amedée Island in New Caledonia, $\left(22^{\circ} 28^{\prime} 40^{\prime \prime} \mathrm{S}, 166^{\circ} 28^{\prime} 22^{\prime \prime} \mathrm{E}\right), 15 \mathrm{~m}$ water depth in fine sand and Station 4, north side of Recif Tamanou, (22 $\left.18.866 \mathrm{~S}, 166^{\circ} 29.609 \mathrm{E}\right)$, at $2 \mathrm{~m}$ water depth in fine sand.

Other Material examined. Living specimens in squeeze preparations.

Etymology. Species name honors professor Jean-Lou Justine.

Description. Living specimens up to $700 \mu \mathrm{m}$ long and $\sim 150 \mu \mathrm{m}$ wide. Body shape variable, especially when compressed, but mainly cylindric, long and slender (Fig. 23A). Anterior end rounded, posterior end tapering. Specimens fixed for histological sectioning highly contracted.

Epidermis completely ciliated with $5 \mu \mathrm{m}$ long cilia. Body mostly colorless by transmitted light, except some yellow to orange coloration, laterally, possibly food particles (Fig. 23ABC).

Numerous vacuoles located in posterior part of body, mostly posterior to ovary, small with little variability in size, $\sim 20 \mu \mathrm{m}$ in diameter (Fig. 23AC). Statocyst $5 \mu \mathrm{m}$ in diameter, located $250 \mu \mathrm{m}$ from anterior end, at U12. Frontal organ present, cell bodies of frontal organ extend from statocyst to posterior part of pharynx, U13 to U25. Mouth opening on ventral surface, posterior to statocyst, at U20, opens to ciliated pharynx with glandular epithelium, wavy or undulatory-shaped, extending from U20 to U30 (Fig. 23AB). Pharynx visible in compressed living specimens. Digestive central syncytium diffuse. 

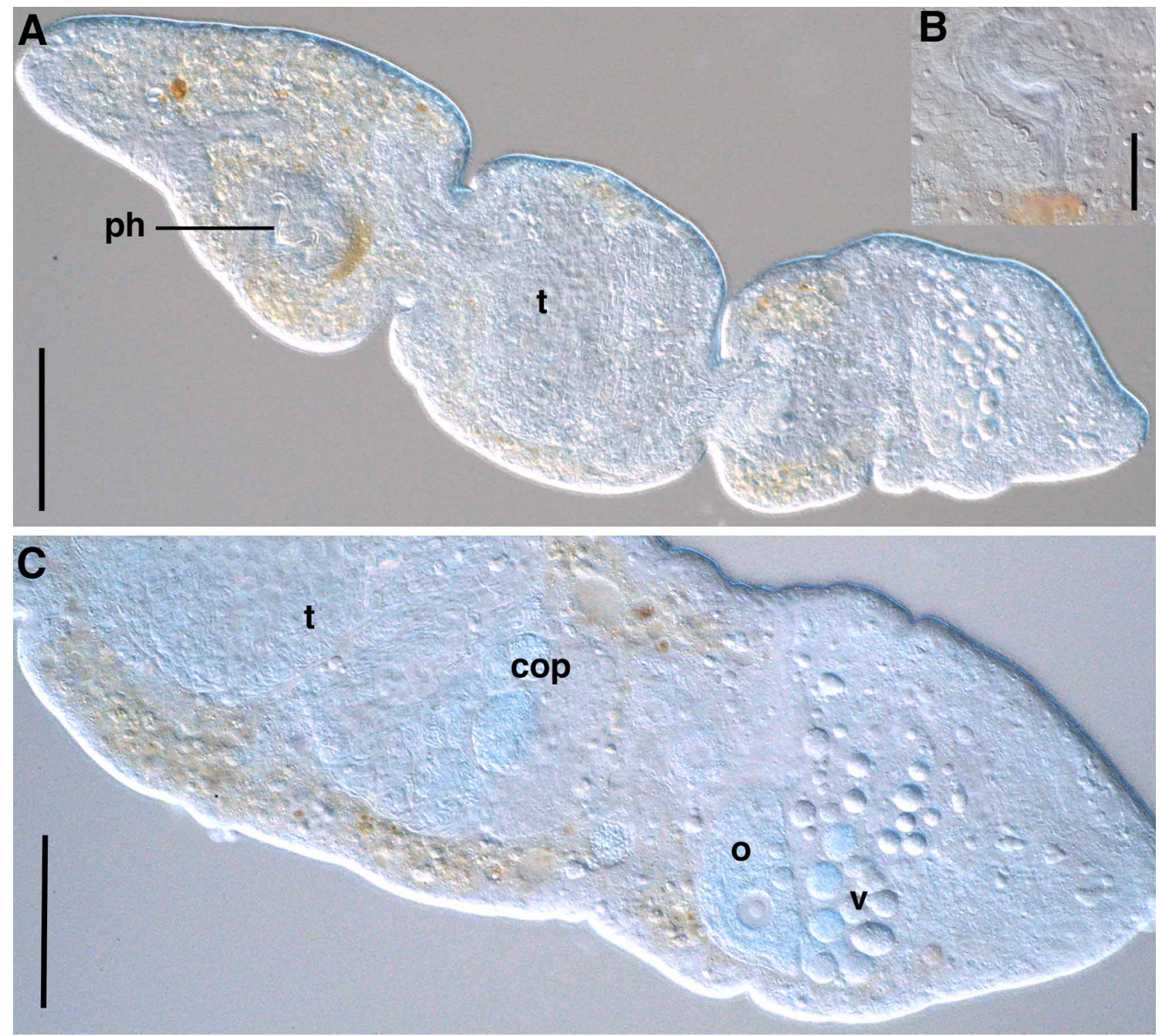

FIGURE 23. Solenofilomorpha justinei sp.nov. Photomicrographs of living specimens. A. Dorsal view of whole specimen. Scale bar: $100 \mu \mathrm{m}$. B. View of posterior part of body. Scale bar: $50 \mu \mathrm{m}$. C. Showing pharynx. Scale bar: $40 \mu \mathrm{m}$.

Ovary unpaired, ventral, with up to 4 oocytes, reaching posterior to male copulatory organ, extending from U50 to U90 (Fig. 23C). In sectioned specimens oocytes are located more anteriorly, this may be a fixation artifact. Seminal bursa absent in all specimens found. Sperm found posterior to antrum, dorsal to the oocytes, interpreted as allosperm. Testes unpaired, dorsal, separated from ovary, extending from seminal vesicle anterior to middle of body (Figs. 23A, 24AC), U35 to U60. Male gonopore located in posterior to mid-body, at U62, opens to ciliated antrum, $25 \mu \mathrm{m}$ long. Proximal end of antrum opens to spherical seminal vesicle, at U62, $30 \mu \mathrm{m}$ in diameter. Eosinophilic glands located in proximal part of antrum.

Remarks. The Bayesian analysis of nucleotide data places this species in the Solenofilomorphidae with maximum support, but there is limited resolution within this clade (Fig 26). Morphological support for classifying this species in Solenofilomorphidae is derived from the unpaired testis and ovary located posterior to the male copulatory organ, which is positioned in the mid-body, and from its ciliated anterior pharynx. 

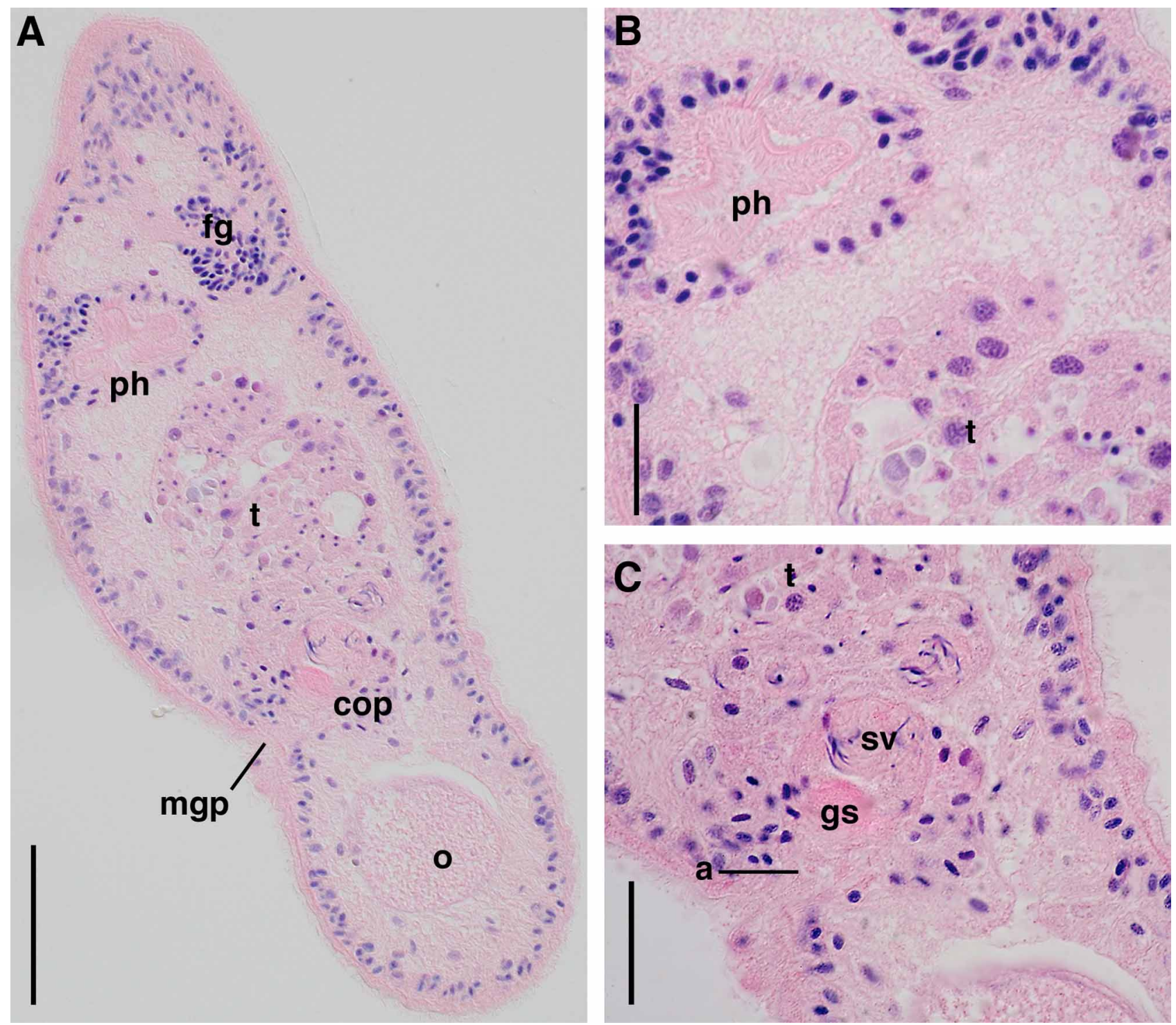

FIGURE 24. Solenofilomorpha justinei sp.nov. Photomicrographs of sagittal histological sections stained with hematoxylineosin. A. Section through length of body. Scale bar: $60 \mu \mathrm{m}$. B. Section through posterior. Scale bar: $30 \mu \mathrm{m}$. C. Showing pharynx and testes. Scale bar: $30 \mu \mathrm{m}$.

Solenofilomorpha justinei can be identified as a member of the genus Solenofilomorpha due to its tubiform pharynx with glandular epithelium and the lack of rhammites and penis.

This species is distinguished from other species of Solenofilomorpha by the following characters: pharynx tubular with undulatory shape, body short $(700 \mu \mathrm{m}$ ), and wide, (length /width about 5), lack of pigmentation, absence of seminal bursa, simple male copulatory organ consisting of seminal vesicle without well-developed penis, and massive testes reaching anteriorly to U35.

Solenofilomorpha longissima Dörjes, 1968 also lacks a seminal bursa, but there is a small muscular penis, the testis is much smaller and oocytes are larger and more numerous than in $S$. justinei. Moreover, the pharynx is more anterior in S. longissima, the body is much longer $(1900 \mu \mathrm{m})$ and vacuoles are absent. In Solenofilomorpha guamensis Crezee, 1975 a seminal bursa is present, numerous glands surround the proximal part of the male antrum, the reproductive organs are more anterior and the pharynx is located more posteriorly in comparison to $S$. justinei. Solenofilomorpha funilis Crezee, 1975 has a seminal bursa, the pharynx is located more posteriorly than in S. justinei and the posterior vacuoles are much larger. Both S. guamensis and S. funilis swim with anterior part of the body straight and the posterior curved, whereas $S$. justinei swims with straight body. 
A

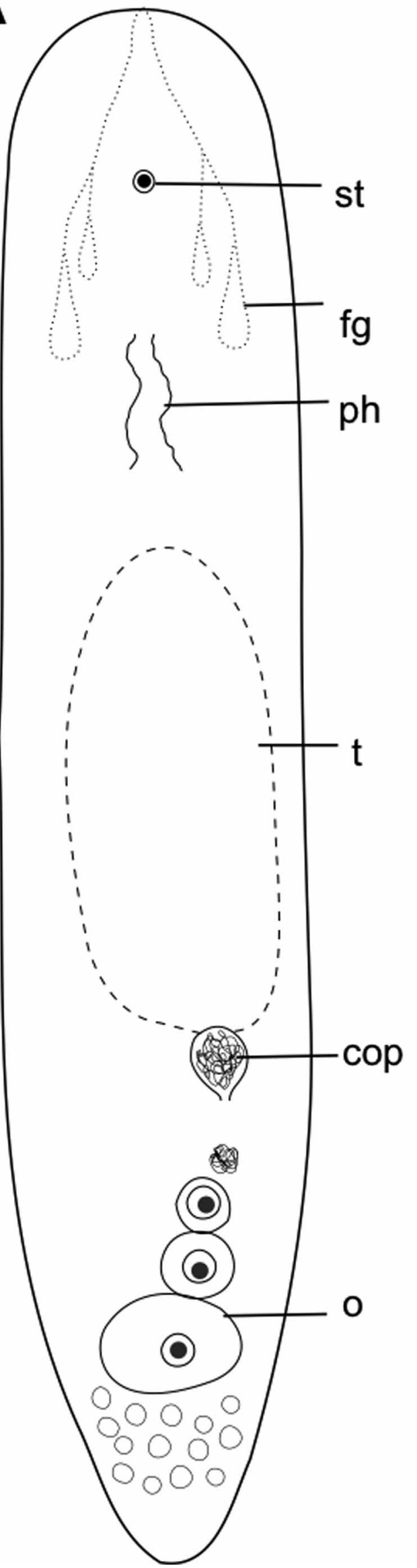

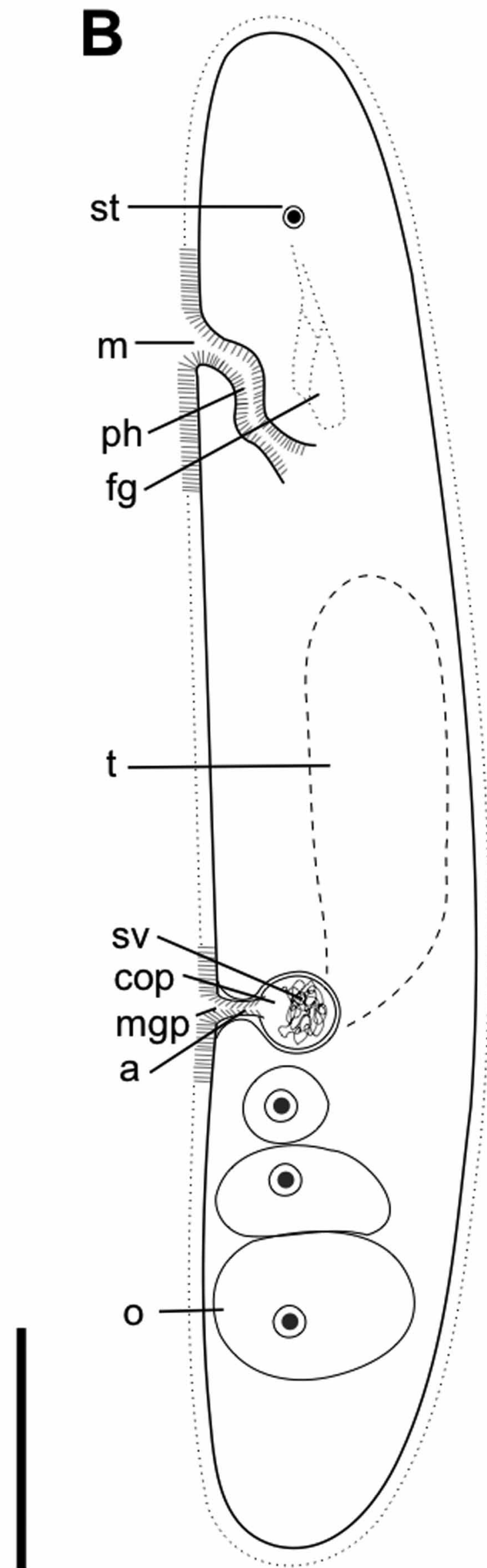

FIGURE 25. Solenofilomorpha justinei sp.nov. Reconstructions show arrangement of organs. A. Dorsal reconstruction of whole living animal. B. Sagittal reconstruction of the whole animal. Scale bar: $100 \mu \mathrm{m}$. 


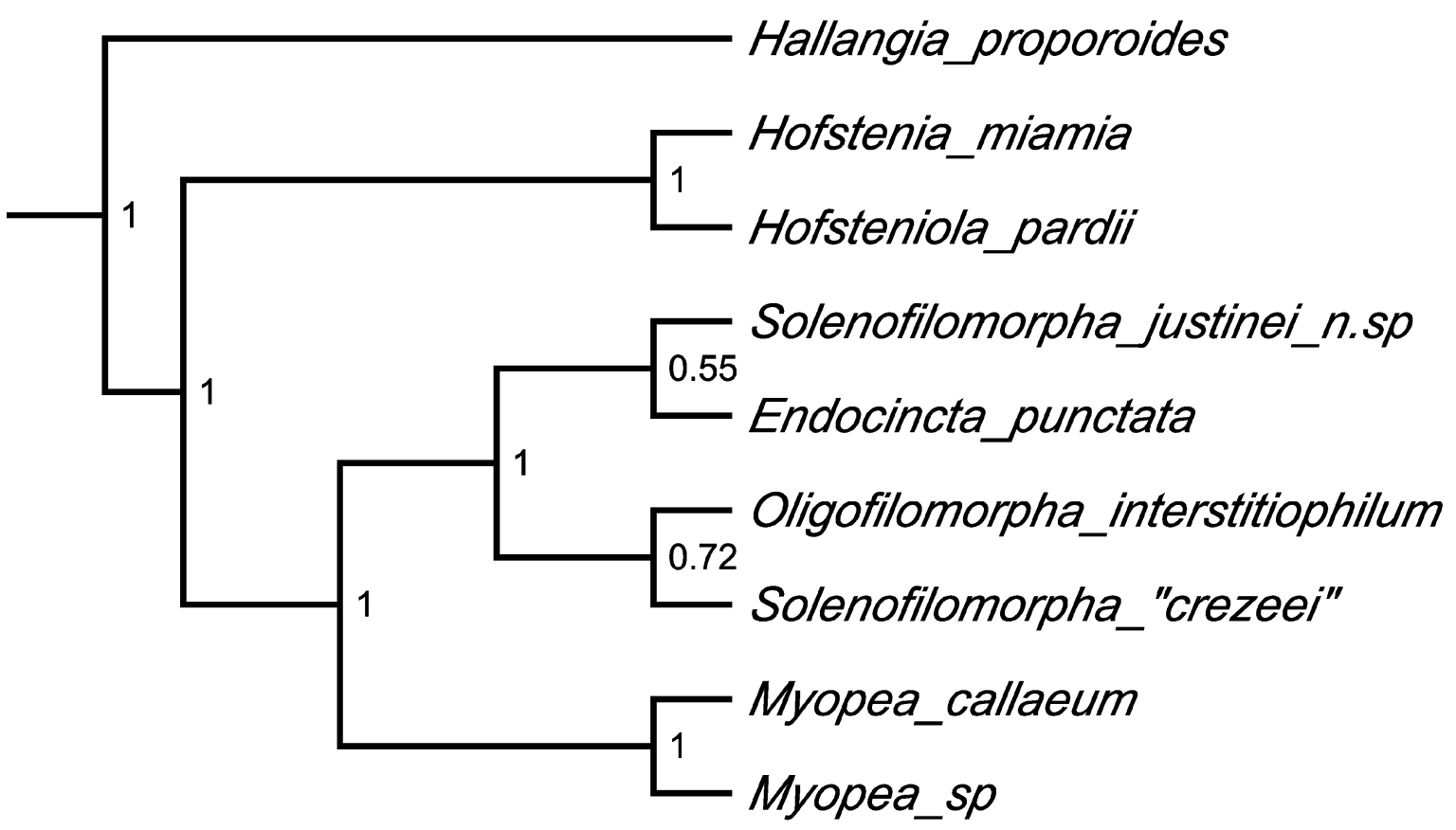

FIGURE 26. Detail from the majority rule consensus tree summarizing the result of the Bayesian analysis of the combined $18 \mathrm{~S}$ rDNA, 28S rDNA and COI dataset with the GTR+G substitution model after 10 million generations sampled every 1000 generations after a burnin of 5 million generations. Solenofilomorpha justinei $n$.sp groups with other Solenofilomorphidae species with maximum support, although there is low support for relationships within the clade.

\section{Acknowledgements}

We received support from the ASSEMBLE research infrastructure initiative (ASSEMBLE grant agreement no. 227799) for the field work at the Interuniversity Institute in Eilat and the Stazione Zoologica Anton Dohrn Ischia/ Naples which is gratefully acknowledged. Many thanks to professor Marco Curini Galletti for inviting us to the workshops in La Maddalena and Castiglione.

Thanks are also extended to professor Jean-Lou Justine for kind assistance with our field work at IRD in Noumea, New Caledonia. We would also like to thank Dr Maria Christina Gambi for providing samples from the carbon dioxide vents at Ischia. Financial support was received from the Swedish Research council, grant to Ulf Jondelius.

\section{References}

Achatz, J.G. (2008) Convolutidae (Acoela) from the Andaman Sea. Zootaxa, 1824, 1-16.

Achatz, J.G. \& Hooge, M.D. (2006) Convolutidae (Acoela) from Tanzania. Zootaxa. 1362, 1-21.

Aescht, E., Mulisch, M. \& Welsch, U. (2010) Romeis Mikroskopische Technik, 18 Auflage. Spektrum Akademischer Verlag.

Ax, P. \& Dörjes, J. (1966) Oligochoerus limnophilus nov. spec. ein kaspisches Faunenelement als erster Süßwasservertreter der Turbellaria Acoela in Flüssen Mitteleuropas. Internationale Revue der Gesamten Hydrobiologie, 51, 15-44.

Bartolomaeus, T. \& Balzer I. (1997) Convolutriloba longifissura nov. spec. (Acoela) -- the first case of longitudinal fission in Plathelminthes. Microfauna Marina, 11, 7-18.

Beklemischev W.N. (1915) Sur les Turbellaries parasites de la co^te Mourmanne. I. Acoela. Proceedings of the Petrograd Imperial Society of Naturalists, 4, 103-172.

Crezee, M. (1975) Monograph of the Solenofilomorphidae (Turbellaria: Acoela). International Review of Hydrobiology, 60, $769-845$.

Dörjes, J. (1968) Die Acoela (Turbellaria) der deutschen Nordseeküste und ein neues System der Ordnung. Journal of Zoological Systematics and Evolutionary Research, 6, 56-452.

Faubel, A. (1974) Die Acoela (Turbellaria) eines Sandstrandes der Nordseeinsel Sylt. Mikrofauna Meeresbodens, 32, 1-58.

Graff, L. von. (1882) Monographie der Turbellarien I. Rhabdocoelida. (2 Vol., Leipzig). Verlag Wilhelm Engelmann, Leipzig, $1-442 \mathrm{pp}$. 
Graff, L. von. (1910) Vergleichung der nordamerikanischen und europäischen Turbellarienfauna. The University Press, Cambridge MA., pp. 944-948.

Hall-Spencer J. M., Rodolfo-Metalpa R., Martin S., Ransome E., Fine M., Turner S. M., Rowley S. J., Tedesco D. \& Buia M. (2008) Volcanic carbon dioxide vents show ecosystem effects of ocean acidification. Nature, 454, 96-99.

Haswell, W.A. (1905) Studies of the Turbellaria. Part I. On Heterochaerus, an "Acoelous" Turbellarian. Part II. On Aromalocoelus caecus, a new type of Rhabdocoele. Journal of Cell Science, 49, 425-467.

Hejnol, A., Obst, M., Stamatakis, A., Ott, M., Rouse, G.W., Edgecombe, G.D., Martinez, P., Baguñà, J., Bailly, X., Jondelius, U., Wiens, M., Müller, W.E., Seaver, E., Wheeler, W.C., Martindale, M.Q., Giribet, G. \& Dunn, C.W. (2009) Assessing the root of bilaterian animals with scalable phylogenomic methods. Proceedings. Biological Sciences/The Royal Society, 276, 4261-70.

Hickman, V.V. (1956) Parasitic Turbellaria from Tasmanian Echinoidea. Papers \& Proceedings of the Royal Society of Tasmania, 90, 169-181.

Hooge, MD. (2001) Evolution of body-wall musculature in the Platyhelminthes (Acoelomorpha, Catenulida, Rhabditophora). Journal of Morphology, 249, 171-194.

Hooge, M.D. (2003) Two new families, three new genera, and four new species of acoel flatworms Acoela, Platyhelminthes) from Queensland, Australia. Cahiers de Biologie Marine, 44, 275-298.

Hooge, M.D. \& Rocha C. E. F. (2006) Acoela (Acoelomorpha) from the northern beaches of the state of São Paulo, Brazil, and a systematic revision of the family Otocelididae. Zootaxa, 1335, 1-50.

Hooge, MD. \& Tyler, S. (2005) New tools for resolving phylogenies: A systematic revision of the Convolutidae (Acoelomorpha, Acoela). Journal of Zoological Systematics and Evolutionary Research, 43, 100-113.

Huelsenbeck, J.P. \& Ronquist, F. (2001) MRBAYES: Bayesian inference of phylogenetic trees. Bioinformatics, 17, 754-755.

Jondelius, U., Ruiz-Trillo, I., Baguna, J. \& Riutort, M. (2002) The Nemertodermatida are basal bilaterians and not members of the Platyhelminthes. Zoologica Scripta, 31, 201-215.

Jondelius, U., Wallberg, A., Hooge, M.D. \& Raikova, O. (in press) How the Worm Got its Pharynx: Phylogeny, Classification and Bayesian assessment of Character Evolution in Acoela. Systematic Biology.

Katoh, K., Asimenos, G. \& Toh, H. (2009) Multiple alignment of DNA sequences with MAFFT. Methods in Molecular Biology, 537, 39-64.

Katoh, K. \& Toh, H. (2008) Improved accuracy of multiple ncRNA alignment by incorporating structural information into a MAFFT-based framework. BMC Bioinformatics, 9, 212.

Kolasa, J. \& Faubel, A. (1974) A preliminary description of a freshwater Acoela (Turbellaria): Oligochoerus polonicus nov. spec. Italian Journal of Zoology, 41, 2, 81-85.

Leiper, RT. (1902) On an acoelous turbellarian inhabiting the common heart urchin. Nature London, 66, 641.

Marcus, E. (1948) Turbellaria do Brasil. Boletim da Faculdade de Filosofia, Ciências e Letras da Universidade de São Paulo, série Zoologia, 3, 111-243.

Marcus, E. (1950) Turbellaria Brasileiros. Boletim da Faculdade de Filosofia, Ciências e Letras da Universidade de São Paulo, série Zoologia, 15, 5-192.

Marcus, E. (1954) Turbellaria Brasileiros (11). Boletim da Faculdade de Filosofia, Ciências e Letras da Universidade de São Paulo, série Zoologia, 24, 419-489.

Marcus, E. (1957) On Turbellaria. On terrestrial triclads, Convoluta, Hofstenia, Notoplana chierchiae, Itannia ornata, Cestoplana. Anais da Academia Brasileira de Ciências, 29, 153-191.

Martens, H. (1984) Comparison of three different extraction methods for Turbellaria. Marine Ecology - Progress Series, 14, 229-234.

Reuter, M., Raikova, O.I., Jondelius, U., Gustafsson, M.K.S., Maule, A.G. \& Halton, D.W. (2001) Organisation of the nervous system in the Acoela: an immunocytochemical study. Tissue Cell, 33, 119-128.

Ronquist, F. \& J. P. Huelsenbeck. (2003) MRBAYES 3: Bayesian phylogenetic inference under mixed models. Bioinformatics, 19, 1572-1574.

Ruiz-Trillo, I., Paps, J., Loukota, M., Ribera, C., Jondelius, U., Baguna, J. \& Riutort, M. (2002) A phylogenetic analysis of myosin heavy chain type II sequences corroborates that Acoela and Nemertodermatida are basal bilaterians. Proceedings of the National Academy of Sciences of the United States of America, 99, 11246-11251.

Ruiz-Trillo, I., Riutort, M., Littlewood, D.T.J., Herniou, E. \& Baguna, J. (1999) Acoel flatworms: earliest extant bilaterian metazoans, not members of Platyhelminthes. Science (Washington D.C), 283, 1919-1923.

Telford, M.J., Lockyer, N.E., Cartwright-Finch, C. \& Littlewood, D.T.J. (2003) Combined large and small subunit ribosomal RNA phylogenies support a basal position of the acoelomorph flatworms. Proceedings of the Royal Society Biological Sciences, Series B, 270, 1077-1083.

Wallberg, A., Curini-Galletti, M., Ahmadzadeh, A. \& Jondelius, U. (2007) Dismissal of Acoelomorpha: Acoela and Nemertodermatida are separate early bilaterian clades. Zoologica Scripta, 6, 509-523.

Westblad, E. (1942) Studien ueber skandinavische Turbellaria Acoela. II. Arkiv för Zoologi, 33A(14), 1-48.

Westblad, E. (1945) Studien ueber skandinavische Turbellaria Acoela. III. Arkiv för Zoologi, 36A(5), 1-56.

Westblad, E. (1946) Studien ueber skandinavische Turbellaria Acoela. IV. Arkiv för Zoologi. 38A(1), 1-56.

Westblad, E. (1948) Studien ueber skandinavische Turbellaria Acoela. V. Arkiv för Zoologi. 41A(7), 1-82. 
TABLE 1: New sequences and their GenBank accession numbers.

\begin{tabular}{|c|c|c|c|c|c|c|c|}
\hline Species & $\begin{array}{l}\text { Specimen } \\
18 S\end{array}$ & $\begin{array}{l}\text { Accession nr. } \\
18 S\end{array}$ & $\begin{array}{l}\text { Specimen } \\
28 S\end{array}$ & $\begin{array}{l}\text { Accession nr. } \\
28 S\end{array}$ & $\begin{array}{l}\text { Specimen } \\
\text { CO1 }\end{array}$ & $\begin{array}{l}\text { Accessionnr. } \\
\text { CO1 }\end{array}$ & Location \\
\hline Childia aculifera & $\begin{array}{l}0837 \\
0840\end{array}$ & $\begin{array}{l}\text { FR837684, } \\
\text { FR832390 }\end{array}$ & 0837 & FR837768 & 0840 & FR832380 & GenBank \\
\hline Childia curinii & $\begin{array}{l}0921, \\
0923\end{array}$ & $\begin{array}{l}\text { FR832391, } \\
\text { FR832393 }\end{array}$ & & & $\begin{array}{l}0921, \\
0923\end{array}$ & $\begin{array}{l}\text { FR832381, } \\
\text { FR832383 }\end{array}$ & GenBank \\
\hline Pharyngia furva & 1035 & FR832392 & 1035 & FR832400 & 1035 & FR832382 & GenBank \\
\hline Philactinoposthia brevis & $\begin{array}{l}1010, \\
1011\end{array}$ & $\begin{array}{l}\text { FR832394, } \\
\text { FR832395 }\end{array}$ & $\begin{array}{l}1010 \\
1011\end{array}$ & $\begin{array}{l}\text { FR832404, } \\
\text { FR832402 }\end{array}$ & $\begin{array}{l}1010, \\
1011\end{array}$ & $\begin{array}{l}\text { FR832384, } \\
\text { FR832385 }\end{array}$ & GenBank \\
\hline Philactinoposthia ischiae & $\begin{array}{l}10223, \\
10231, \\
10245\end{array}$ & $\begin{array}{l}\text { FR832396, } \\
\text { FR832397, } \\
\text { FR832398 }\end{array}$ & 10245 & FR832403 & $\begin{array}{l}10223, \\
10231, \\
10245\end{array}$ & $\begin{array}{l}\text { FR832386, } \\
\text { FR832387, } \\
\text { FR832388 }\end{array}$ & GenBank \\
\hline $\begin{array}{l}\text { Philactinoposthia } \\
\text { novaecaledoniae }\end{array}$ & 0865 & FR837728 & 0865 & FR837812 & 0865 & FR837882 & GenBank \\
\hline $\begin{array}{l}\text { Solenofilomorpha } \\
\text { justinei }\end{array}$ & 0876 & FR832399 & 0876 & FR832404 & 0876 & FR832389 & GenBank \\
\hline
\end{tabular}

